\title{
CONVERGENCIA DIGITAL EN LA UNIVERSIDAD COLOMBIANA. DEL SIGLO XX AL XXI
}

\author{
Diana Elvira Soto Arango ${ }^{1}$ \\ Universidad Pedagógica y Tecnológica de Colombia \\ Grupo de Investigación HISULA \\ dianaelvirasoto@gmail.com \\ Fredy Yesid Mesa Jiménez ${ }^{2}$ \\ Universidad Pedagógica y Tecnológica de Colombia \\ Grupo de Investigación HISULA \\ fredy.mesa@uptc.edu.co \\ Edgar Orlando Caro ${ }^{3}$ \\ Universidad Pedagógica y Tecnológica de Colombia \\ Grupo de Investigación HISULA \\ edgar.caro@gmail.com
}

Recepción: 18/10/2012

Evaluación: 29/10/2012

Aceptación: 15/11/2012

Artículo de Revisión

doi: http://dx.doi.org/10.9757/Rhela.19.12

\section{RESUMEN}

La investigación presenta los orígenes de la convergencia digital ${ }^{4}$ desde la tecnología educativa, con la educación programada, la evolución, tendencias teóricas y la prospectiva en el contexto universitario colombiano. El período de estudio se enmarca desde el siglo XX, con la tecnología educativa hasta la prospectiva en el siglo XXI, con el reto de integrar las innovaciones tecnoló-

\footnotetext{
1 Profesora titular de la Universidad Pedagógica y Tecnológica de Colombia máxima categoría. Con doctorado y posdoctorado. Estudió en la UNED y trabajo en la UNED de Guinea Ecuatorial. Organizó en 1996 y fue la primera Directora del Doctorado en Ciencias de la Educación de RUDECOLOMBIA. Organizó en 1992 la Sociedad de Historia de la Educación Latinoamericana y es la Directora de los Grupos de Investigación: Historia y Prospectiva de la Universidad Latinoamericana-HISULA y la Ilustración en América Colonial - ILAC, visibles en COLCIENCIAS.

2 Candidato a Doctor en Ciencias de la Educación de RUDECOLOMBIA. Docente asistente de la Universidad Pedagógica y Tecnológica de Colombia (UPTC) e integrante del grupo de Investigación Historia y Prospectiva de la Universidad Latinoamericana - HISULA, adscrito a la UPTC.

3 Candidato a Doctor en Ciencias de la Educación de RUDECOLOMBIA. Docente asistente de la Universidad Pedagógica y Tecnológica de Colombia (UPTC) e integrante del grupo de Investigación Historia y Prospectiva de la Universidad Latinoamericana - HISULA, adscrito a la UPTC.

4 Para este trabajo, es entendida como una mezcla y unificación de innovaciones tecnológicas (en uno o varios dispositivos) que permiten almacenar y acceder a múltiples medios de información, con un potencial de cambio e innovación.
} 
gicas, para optimizar la calidad en las funciones misionales, la competitividad, el reconocimiento y la cobertura estudiantil en el nivel universitario. Por tanto, analizamos algunas experiencias de influencia de la unificación de medios y la forma como se pueden beneficiar las instituciones universitarias dentro del contexto de la legislación colombiana. El método se sustentó en la historia social de la educación con la metodología de la educación comparada. Las estrategias se soportaron en fuentes documentales de legislación, informes y la bibliografía acompañada de proyectos en desarrollo. Se concluye cómo la convergencia digital permite la fusión de las

\section{DIGITAL GATHERING IN COLOMBIAN UNIVERSITIES. TOWARDS XXI CENTURY}

\section{ABSTRACT}

This work aims towards a fundamental review on evolution, prospective and basis of "Digital Gathering" in the Colombian university context, due to the technology and education integration challenge in order to improve quality of its mission, competitive standards, recognition and higher education.Every year higher education institutions invest large amounts of money in order to innovate their technological appliances and its teachers' quality, this sometimes may not be a solid evidence of pedagogical improves nor pedagogical transformation in its academy community because of its use, besides, digital technology advance might sometimes represent a variation in subject's culture while having to forget what was once learned in order to re-learn again. Therefore, this document analyses some cases of difficulties while making this "digital gathering of knowledge" and the way in which all higher education institutions can benefit. This research involved a deep review of document sources and advance reports' about projects in development phase, in RUDECOLOMBIA $\mathrm{CPTU}^{5}$ Education Sciences PhD Program's office framework. "Digital Gathering" is an opportunity to join all areas of Information and Communication Technologies (ICT) ${ }^{6}$ at universities

5 T. N. Colombian Pedagogical and Technological University.

6 In Colombian framework, National Estadistics Department (NED) accepted in 2003 the term ICT as: "group of tools, gadgets or communication media such as mobile technollogy, computers, e mail, and internet that make possinle all com- dependencias en Tecnologías de la Información y la Comunicación (TIC) de las universidades, para producir contenidos y servicios académicos, cambios en los hábitos de consumo de información por parte de los sujetos sociales y generar actitudes colaborativas y de aprendizaje autónomo, que permiten aportar a los procesos de enseñanza y aprendizaje y a la construcción de conocimiento desde cualquier momento y lugar.

Palabras clave: Revista Historia de la Educación Latinoamericana, convergencia digital, TIC, universidad.

\section{CONVERGÊNCIA DIGITAL NA UNIVERSIDADE COLOMBIANA. RUMO AO SÉCULO XXI}

\section{RESUMO}

Este trabalho realiza uma revisão sobre a fundamentação, evolução e prospectiva da tendência denominada "convergência digital" no contexto universitário colombiano, devido ao desafio de integrar as tecnologias na educação para melhorar a qualidade de suas funções missionais, a competitividade, o reconhecimento e a cobertura estudantil. Anualmente as instituições universitárias realizam altas inversões em inovação tecnológica e formação docente, que em ocasiões não evidenciam transformações pedagógicas e sua apropriação por parte da comunidade acadêmica. Ademais, as tecnologias digitais ocasionam variações na cultura dos sujeitos, o que implica um desprendimento para voltar a aprender. Portanto, o texto analisa alguns casos de influência da convergência digital e a forma como podem se beneficiar as instituições universitárias. Este trabalho envolveu uma revisão minuciosa de fontes documentais e avanços de projetos em desenvolvimento, no marco do doutorado em Ciências da Educação de RUDECOLOMBIA CADE-UTPC. A convergência digital é uma oportunidade para fusionar as dependências em Tecnologias da Informação e da Comunicação (TIC) $^{7}$ das universidades, produzir conteúdos

No caso da Colômbia, o departamento Administrativo Nacional de Estatística (DANE) adotou em 2003 a definição de TIC "como o conjunto de instrumentos, ferramentas ou meios de comunicação como a telefonia, os computadores, o correio eletrônico e a internet que permitem comunicar-se entre si com pessoas e organizaçóes". Departamento 
for content development and academy services taking advantage of individuals' information necessity in order to stimulate collaborative attitudes and self-learning habits that may add to both teaching and learning processes and knowledge development at any moment and any place.

Key words: History of Latin American Education Journal, Digital Gathering, ICT, University. e serviços acadêmicos, aproveitar as mudanças nos hábitos de consumo de informação por parte dos sujeitos e gerar atitudes colaborativas e de aprendizagem autônoma que permitam contribuir com os processos de ensino e aprendizagem e com a construção do conhecimento a partir de qualquer lugar.

Palavras-chave: Revista História da Educação Latino-americana, convergência digital, TIC, universidade. munications between people or organizations" , National Estadistics Department (NED), "Metrics of Information and Communication Technologies. Executive Brief". (2003). http://www.dane. gov.co/files/investigaciones/tics/tics.pdf (february 12 2013). Also at: Law 13412009 (6th article) which defines basic principles and concepts on information society and ICT managment, ICT as "group of tools, gadgets, resources, equipment, software, apps, network or media used in process compilation, of information transmition and backup in: voice, text, images, video or data”.
Administrativo Nacional de Estatística, "Medición de las Tecnologías de la Información y las Comunicaciones. Resumen Ejecutivo". (2003). http://www. dane.gov.co/files/investigaciones/tics/tics.pdf (12 de fevereiro de 2013). Na lei 1341 de 2009 (Artículo 6), se define os princípios e os conceitos sobre a sociedade da informação e a organização das TIC, são definidas como "o conjunto de recursos, ferramentas, equipes, programas informáticos, aplicaçōes, redes e meios que permitam a compilaçáo, processamento, armazenamento, transmissão de informação como: voz, dados, texto, vídeo e imagens".

\section{INTRODUCCIÓN}

El reflexionar sobre el futuro de las universidades colombianas y latinoamericanas, desde la convergencia digital, nos lleva a plantearnos la viabilidad de las TIC $^{8}$ en un medio donde se abre camino la educación virtual que partió de la educación a distancia ${ }^{9}$. Partimos del hecho, que se ha analizado en otras ocasiones que "no podemos actualmente proyectar la universidad sin analizar las tendencias de desarrollo de esta institución dentro de la "sociedad del conocimiento" 10 que "articula nuevos procesos sociales, que involucran espacios físicos, mentales, de comunicación y nuevos

8 Para el caso de Colombia, el Departamento Administrativo Nacional de Estadística (DANE) adoptó en 2003 la definición de TIC "como el conjunto de instrumentos, herramientas o medios de comunicación como la telefonía, los computadores, el correo electrónico y la internet que permiten comunicarse entre sí a las personas u organizaciones" Departamento Administrativo Nacional de Estadística, "Medición de las Tecnologías de la Información y las Comunicaciones. Resumen Ejecutivo". (2003). http://www.dane.gov.co/files/investigaciones/tics/ tics.pdf (12 de febrero de 2013). En la Ley 1341 de 2009 (artículo 6), la cual define los principios y conceptos sobre la sociedad de la información y la organización de las TIC, son definidas como "el conjunto de recursos herramientas, equipos, programas informáticos, aplicaciones, redes y medios, que permiten la compilación, procesamiento, almacenamiento, transmisión de información como: voz, datos, texto, video e imágenes".

9 La educación a distancia en la parte conceptual conlleva la disposición al aprendizaje desde el trabajo al propio ritmo utilizando diferentes metodologías y evaluación continua. La diferencia con la educación virtual es que esta última interactúa fundamentalmente en un espacio de internet con simulaciones y agentes no reales.

10 Diana Soto Arango, "La Universidad Latinoamericana. Un futuro en construcción", en Independencia e Universidade NaAmérica Latina. Tradicoes, Tempos e territórios, José Rubens Lima Jardilino, Leandro 
actores" ${ }^{\prime 11}$. Actualmente, esta sociedad del conocimiento debe considerar hacia dónde va la universidad con una población mundial estudiantil que se calcula para el 2025 en 262 millones $^{12}$ y que en Colombia para diciembre de 2011 se establecía, en total para las 288 Instituciones de Educación Superior, una matrícula de 1.876 .000 estudiantes de los cuales el 54,8\% correspondía a las públicas y el $45,2 \%$ a las privadas. Se reconoce que la cobertura, de la matrícula universitaria, es deficiente y que las políticas gubernamentales se encaminan a ampliar la misma en 2012 con $202.000 \mathrm{cu}-$ pos y en el 2013 con 674.272 para lograr estas metas en 2014 el 50\% de esta matrícula ${ }^{13}$. Además, hay que decir, que se pone en la palestra, dentro de las políticas del Estado colombiano, el promover la educación virtual con la exigencia de la utilización de las TIC en todos los programas académicos ${ }^{14}$. Por otra parte, la realidad es que las Instituciones de Educación Superior en Colombia (IES) no son ajenas a la actual sociedad de la información y el conocimiento, que presenta la apertura de fronteras hacia las tendencias internacionales de integrar las tecnologías digitales en la educación. Se debe reconocer que las universidades colombianas realizan inversiones en innovación tecnológica que ocasionan variaciones en la cultura de los sujetos y sin embargo, en algunos casos, no se refleja en transformaciones pedagógicas y de apropiación de estas, por parte de la comunidad académica.

Las preguntas centrales, que continuamos planteando ${ }^{15}$, giran sobre: ¿En qué medida la educación superior ha sido el motor del desarrollo

de Proença Lopes, Valéria Andrade Silva (Orgs.)(Sao Paulo: Paco Editorial. Sociedad de Historia de la Educación Latinoamericana, 2011), 193-234. "El conocimiento se ha convertido en objeto de inmensos desafíos económicos, políticos y culturales, hasta tal punto que las sociedades cuyos contornos empezamos a vislumbrar bien pueden calificarse de sociedades del conocimiento". Jerónimo Binde, Hacia las sociedades del conocimiento. Informe mundial de la UNESCO (París: Ediciones UNESCO, 2005), 5. www.unesco.org/publications (25 de mayo de 2010).

11 Proyecto de investigación "Universidad y Nación”. Grupo de investigación "Historia y prospectiva de la universidad Latinoamericana. HISULA”. Dirección de Investigaciones, Universidad Pedagógica y Tecnológica de Colombia. 2009.

12 UNESCO, "La Nueva Dinámica de la Educación Superior y la búsqueda del cambio social y el Desarrollo", en Conferencia Mundial de Educación Superior (París: Comunicado final, 2009).

13 De acuerdo con el SNIES, SACES, Observatorio de la Universidad. Documentos de política educativa del Ministerio de Educación Nacional. 2011-2012. Revisado en webs de septiembre, octubre de 2012.

14 Según el decreto 1295 del 20 de abril de 2010. Art. 5.8 indica "Disponibilidad y capacitación para el uso de por lo menos los siguientes medios educativos: recursos bibliográficos y de hemeroteca, bases de datos con licencia, equipos y aplicativos informáticos, sistemas de interconectividad, laboratorios físicos, escenarios de simulación virtual de experimentación y práctica, talleres con instrumentos y herramientas técnicas e insumos, según el programa y la demanda estudiantil real o potencial cuando se trate de programas nuevos.

15 Diana Soto Arango, "Criterios comunes para el desarrollo de una educación universitaria global. Una propuesta latinoamericana”, en Colección Historia y prospectiva de la universidad latinoamericana, tomo II (São Paulo: UNINOVE, Universidad Pedagógica y Tecnológica de Colombia, RUDECOLOMBIA, 2006), 239. 
sostenible dentro de los planes nacionales e internacionales? ¿Ha estado este sector a la altura de las expectativas puestas en él para inducir al cambio y al progreso en la sociedad, y para actuar como factor principal en la construcción de futuras sociedades del conocimiento? ¿Cómo puede la educación superior, utilizando la convergencia digital, contribuir al desarrollo del sistema educativo en general? ¿Cuáles son las tendencias más significativas que moldearán la nueva educación superior y los espacios de investigación desde la virtualidad? ¿De qué manera el aprendizaje y los aprendices están cambiando al incluir nuevas modalidades de aprendizaje virtuales? ¿Cuáles son los nuevos retos para la "calidad" y la "equidad" desde la convergencia digital? ¿Se están asimilando las tecnologías como la enseñanza virtual en una sociedad del conocimiento y de la información ${ }^{16}$, que llevan a una individualidad y que hacen temer el diálogo personal en la universidad? ¿Se desarrollan las competencias necesarias para el uso de la convergencia digital en los procesos de enseñanza y aprendizaje ${ }^{17}$ ¿Tenemos el mismo imaginario, que nuestros colegas de los años sesenta, cuando se preguntaban si la TV y las grabadoras irían a desplazar a los docentes universitarios? ${ }^{\text {18 }}$.

Estas preguntas las analizamos a través de la documentación e investigaciones en experiencias sobre la influencia de la convergencia digital y la forma como se pueden beneficiar las instituciones universitarias en Iberoamérica. Compartimos, en esta investigación desde los orígenes de la tecnología educativa, la incidencia de la educación programada; la evolución, tendencias teóricas, y la prospectiva de las innovaciones tecnológicas en el contexto universitario latinoamericano. El reto que se analiza es el de integrar las tecnologías en la educación para la calidad en las funciones misionales, la competitividad, el reconocimiento y la cobertura estudiantil. Además, teniendo en cuenta que las tecnologías digitales ocasionan variaciones en la cultura de los sujetos en el proceso de desaprender para volver a aprender. El método se sustentó en la

16 Sociedad del Conocimiento como la concibe la UNESCO que incide en transformaciones sociales y culturales.

17 La competencia en el proyecto 6X4 se estableció como la capacidad para realizar una actividad. Diana Soto Arango "La investigación y la innovación en los programas de Historia y Ciencias Sociales en Colombia. Una propuesta desde el Proyecto 6X4”, en Revista Historia de la Educación Latinoamericana, Tunja, No 9, (2007), 203- 230.

18 Examinar el movimiento, las condiciones culturales que lo hacen posible, las personas que estudian y sus roles, las características que distinguen cada periodo y las tendencias que emergen y continúan en el presente. David Portman, The Universities and the public. A history of higher adult education in the United States. (Chicago: Nelson Hall, 1978). 
historia social de la educación, con la metodología de la educación comparada. Las estrategias se soportaron en fuentes documentales, legislación y la bibliografía acompañada de proyectos en desarrollo, en el marco del doctorado en Ciencias de la Educación de RUDECOLOMBIA.

\section{Tecnología educativa versus educación programada, en el camino de la educación a distancia}

La tecnología educativa, hace su aparición en las primeras décadas del siglo XX en Estados Unidos. Un producto de esta la encontramos en la educación programada, que se entendía como "el empleo de instrumentos o máquinas de determinado proceso o método" 19 . Por este motivo, los orígenes de la educación programa la localizamos en las máquinas de enseñar. Quizás, uno de los pioneros más relevantes de la educación programada es B. F. Skinner (1904-1990) ${ }^{20}$, sin embargo, se deben, reconocer los aportes de Sidney L. Pressey quien, en la universidad del Estado de Ohio (1920), construyó una máquina para calificar exámenes, posteriormente la desarrolló como un aparato de enseñanza ${ }^{21}$. Esta máquina consistía en un dispositivo de elección múltiple. En la ventanilla aparecía el ítem con tres respuestas posibles, el alumno elegía la que consideraba correcta oprimiendo el botón correspondiente. El alumno, al obtener la respuesta correcta, inmediatamente recibía lo que se denominaba el refuerzo. La máquina de Pressey no tuvo acogida en su época ${ }^{22}$ porque no expuso claros los objetivos, como sí lo hizo Skinner más adelante.

Debemos señalar que Skinner había iniciado sus experimentos en la Universidad de Harvard hacía el año 1931. Es precisamente, en esta institución, donde los métodos que utilizó en el laboratorio con animales, los trasladó al aprendizaje de los humanos, bajo el principio que "la enseñanza de un niño y el aprendizaje de una rata son procesos similares... el organismo aprende las respuestas que han sido reforzadas" ${ }^{23}$. Ciertamente, estos

\footnotetext{
19 James Armsey y Norman C. Dahll, Tecnología de la enseñanza (México: Editorial Guadalupe, 1975), 17.

20 Burrhus Frederick Skinner, psicólogo norteamericano, inicia sus investigaciones en el laboratorio animal en 1931. Véase en Diana Soto Arango, Temas de controversia en psicología del aprendizaje (Bogotá: Universidad Pedagógica Nacional, 1979), 3. Documento inédito.

21 Diana Soto Arango, Temas de controversia en psicología del aprendizaje, 56.

22 Skinner atribuyó la falta de entusiasmo por los artefactos de Pressey a la inercia cultural y a la índole inadecuada de los principios de aprendizaje que se sustentaban en la década mencionada”. Citado en William Deterline, Introducción a la enseñanza programada (Buenos Aires: Ediciones Troquel, 1969), 22.

23 Burrhus Frederic Skinner, Ciencia y conducta humana. 2 edición (Barcelona: Editor Fontanella, 1971), 23.
} 
estudios le dieron la base para que en 1954 sintetizará sus experiencias con respecto al aprendizaje, en una conferencia sobre "La ciencia de aprender y el arte de enseñar", que dictó en la Universidad de Pittsburgh y además presentó una máquina para enseñar aritmética. Luego, en 1970 presenta su libro Tecnología de la enseñanz $a^{24}$ de amplia difusión en los primeros magíster de "Tecnología educativa" en las universidades colombianas ${ }^{25}$.

Si bien Skinner fue uno de los ideólogos más relevantes en esta tendencia educativa, no podemos dejar de lado la influencia de organismos internacionales como el Centro Audiovisual Internacional Vía Satélite (CAVISAT), que era un organismo privado financiado por empresas comerciales de Estados Unidos como la IT'T, RCA, General Electric. Es más, el presidente Kennedy en el año 1963, en el mensaje presidencial ante el Congreso, resaltaba la importancia de esta nueva tecnología para llevar valores culturales nuevos a otros países ${ }^{26}$.

Sin lugar a dudas la educación programada tuvo eco en toda Latinoamérica. En la Universidad Nacional Autónoma de México, en la Comisión de Nuevos Métodos de Enseñanza, en el año 1973, indicaban que esta forma de enseñanza era un método pedagógico que permite transmitir conocimientos sin la intervención directa de un profesor o monitor, respetando las características específicas del alumno ${ }^{27}$. Es más, se considera que "un programa es una secuencia de material cuidadosamente ordenado y organizado, de manera que asegura las mejores condiciones de aprendizaje posibles para el alumno"28.

Asimismo, seguidores de este método como Gabriel Ofiesh indican que "la instrucción programada es el primer sistema completo de instrucción que haya surgido en el arte de la pedagogía... es una manera sistemática de considerar la enseñanza" ${ }^{29}$. Para este autor lo básico era la conducta terminal. Otro opinión, está dada por Gardner, quien considera que la

24 Burrhus Frederic Skinner, Tecnología de la enseñanza (Barcelona: Editorial Labor, 1970), 25.

25 La Universidad Pedagógica Nacional de Colombia en el año 1976 inició la maestría en Investigación Curricular con el componente de la Tecnología Educativa. Esta Maestría era financiada por el Programa PNUDUNESCO.

26 Diana Soto Arango, Temas de controversia en psicología del aprendizaje (Bogotá: Universidad Pedagógica Nacional, 1979), 83.

27 Diana Soto Arango, Temas de controversia en psicología del aprendizaje, 65.

28 Comisión de nuevos métodos de enseñanza, Enseñanza programada (México: Universidad Nacional de México, 1973), 5

29 Gabriel Ofiesh, Instrucción programada (México: Editorial Trillas, 1973), 32. 
instrucción programada "es el primer sistema válido de tecnología de la enseñanza y el entrenamiento con que haya contado nuestra sociedad" ${ }^{30}$.

Por otra parte, es relevante conocer que la educación programada, enmarcada dentro de la psicología conductista, se difundió en la década de los setenta en América Latina, con el apoyo de la AID, Banco Mundial, Naciones Unidas, que financiaron programas educativos en todos los niveles, para el entrenamiento y difusión de la misma ${ }^{31}$. En esta década las voces de protesta se sustentaron en que este método educativo era "automatizante y mecanizante para el profesor y el alumno, donde se termina con la creatividad y capacidad de análisis del estudiante al impedir la investigación y discusión entre el profesor y estudiante" 32 . Además, por el marcado factor ideológico que expuso Skinner en sus obras, alguna de ellas como Walden Dos, que proyecta una sociedad ideal para el futuro, donde manifiesta que "su corazón pertenece a la eterna minoría, que es la élite inteligente y de raza superior, en cambio, al pueblo hay que condicionarle por su carácter de incompetente y poco capacitado" 33 .

No todo era uniforme. En las universidades se presenta un gran debate y aparecen en la palestra otros autores con otros modelos educativos, que analizan los procesos de enseñanza y aprendizaje, con otros conceptos teóricos como el cognoscitivo que desarrolla Piaget y Ausubel, partiendo del hecho que el "conocimiento se deriva de la acción y conocer un objeto es actuar sobre él y transformarlo" 34 . En Colombia localizamos críticos al modelo educativo conductista, que se asociaba a la utilización de la tecnología, quienes señalaban, como José Galat Noumer, consejero presidencial de Carlos Lleras Restrepo en 1969, que la educación vía satélite le parecía un vasto plan para la ocupación ideológica del continente.

Lo cierto es, que los principios que Skinner señaló desde la psicología, en los años setenta, sobre la utilización del computador como herramienta de

30 Citado por Bernardo Peña Ivis, "Bases para un marco teórico de la tecnología educativa”, en Revista Perspectivas Latinoamericanas, año II, (1978), 36.

31 Diana Soto Arango, Temas de controversia en psicología del aprendizaje (Bogotá: Universidad Pedagógica Nacional, 1978), 84 .

32 Diana Soto Arango, Temas de controversia en psicología del aprendizaje, 84.

33 Burrhus Frederic Skinner, Walden Dos, 3a edición (Barcelona: Editorial Fontanella, 1973), 297-298-301.

34 Jean Piaget, "Science of education and the psychology of de child", en Para comprender a Piaget, Mary Pulaski (Barcelona: Editorial Península, 1975), 16-28. 
control del aprendizaje $e^{35}$, ahora se le conoce como "la idea de usar el ordenador en el proceso educativo, que ya había tomado forma mucho antes de que aparecieran los microordenadores, en la segunda mitad de la década de los setenta" "36. Precisamente, esta unión hace que las ventas de computadoras personales, para usos educativos, despegaran en los años 1980 teniendo en cuenta que los costos de computación van bajando de precio $^{37}$.

No podemos dejar de señalar ese pasado cercano, de la década de los años 80, por la relación informática y educación, con la tecnológica que aparece en la palestra con el nombre de "informática educativa" 38 . Es decir, se introduce la informática en el currículo escolar ${ }^{39}$ y en un crecimiento veloz aparece la educación on-line, que invade la oferta educativa en el internet.

De esta manera, podríamos indicar que en el ámbito educativo colombiano la flexibilidad ${ }^{40}$ curricular, como un mecanismo para la movilidad estudiantil en otros escenarios de aprendizaje, bajo una ruta académica, se une a la evolución y crecimiento de internet, hipermedia ${ }^{41}$, multimedia, elearning ${ }^{42}$, m-learning ${ }^{43}$, web 2.0 y 3.0 $0^{44}$, entre otras aplicaciones,

35 Diana Arango Soto, Temas de controversia en psicología del aprendizaje (Bogotá: Universidad Pedagógica Nacional, 1978).

36 Bernard Poole, Tecnología educativa, Educar para la sociocultura de la comunicación y el conocimiento, 2a edición (Madrid: McGraw-Hill, 1999), 335.

37 Tom Forester, Sociedad de alta tecnologia: la historia de la revolución de la tecnología de la información (México: Siglo Veintiuno Editores, 1992), 199.

38 Jacqueline García, Ambiente con recursos tecnológicos escenarios para la construcción de procesos pedagógicos (San José de Costa Rica: Editorial Universidad Estatal a Distancia, 2004), 19.

39 Álvaro Carvajal Villaplana, "La informática educativa: una reflexión crítica", Revista Electrónica "Actualidades Investigativas en Educación”, vol. 2, No 1 (2002). http://redalyc.uaemex.mx/pdf/447/44720102.pdf (20 de Noviembre de 2011).

40 La flexibilidad curricular la entendemos como el "aceptar los conocimientos de ingreso del estudiante permitiendo homologaciones y el establecimiento de la ruta académica individual; transferencias; ampliación y diversificación de la oferta en el plan de estudios a partir de los diferentes contextos y problemas de las líneas de investigación en las que se enmarcan las tesis doctorales; mecanismos para la movilidad estudiantil en otros escenarios de aprendizaje; ruta académica del estudiante y direcciones de tesis", en Diana Soto Arango, "La flexibilidad curricular. Una estrategia pedagógica del siglo XXI”. (Bogotá: CONACES, Ministerio de Educación Nacional, 2013), 1. Documento inédito.

41 Permite la navegación no lineal a través de nodos de elementos multimediales.

42 Debido a la cantidad de autores, es complejo definir e-learning, pero a modo de referencia se puede decir que son "todas aquellas metodologías, estrategias o sistemas de aprendizaje que emplean tecnología digital y/o comunicación mediada por ordenadores para producir, transmitir, distribuir y organizar conocimiento entre individuos, comunidades y organizaciones", Según Mariano L. Bernárdez, Diseño, producción e implementación de e-learning: Metodología, herramientas y modelos (Bloomington: Author House, 2007), 16.

43 También denominado aprendizaje móvil, "es la metodología de enseñanza con la posibilidad de aprender a través de internet, pero con la máxima portabilidad, interactividad y conectividad”, según Ainhoa Otamendi Herrera, et al., Guía de innovación metodológica en e-learning, (Programa EVA, 2008), 61.

44 La Web 2.0 como la Web 3.0 son expresiones que describen a partir del internet convencional evoluciones que proveen mayor interactividad en las personas y luego a una web semántica con buscadores y acceso a sistemas de información y base de datos, facilitando el movimiento social asequible por múltiples aplicaciones. 
que hacen parte de los medios o herramientas que están apoyando el proceso de enseñanza y aprendizaje de los nuevos programas a distancia, que se presentan para el registro calificado en la CONACES de Colombia. Es así, que en la búsqueda de aprovechar, entre otras, la flexibilidad y optimización en tiempo, espacios, comunicación, interactividad, trabajo activo y colaborativo, las universidades están ubicando la convergencia digital, como una de las tendencias educativas que se imponen en el momento.

En definitiva, podemos concluir que con el paso del tiempo se ha visto cómo, "poco a poco se van incorporando estas nuevas tecnologías de la información y la comunicación al campo de la educación, generando algunos tópicos, falsas expectativas, prejuicios y problemas" $\$ 5$.

Es más, ha influenciado la compleja transición de inversión de tiempo, dinero, infraestructura y cualificación de docentes y estudiantes.

\section{La universidad y su ingreso a la educación a distancia}

Podríamos decir, que paralelamente a las discusiones sobre los nuevos métodos de enseñanza, sustentados en la tecnología educativa y que se desarrollaron en la educación programada, se vislumbra la aplicación de la misma en el nivel universitario. Como es de suponer el ingreso de la tecnología educativa se enmarca dentro del recorrido histórico de la institución. Por ejemplo, son significativas las conclusiones de la Pacific Northwest Conference on Higher Education ${ }^{46}$, que se realizó del 20 al 22 de abril de 1967, en Estados Unidos, donde el objetivo central era plantear una propuesta curricular para la alta educación. Esta conferencia indicó que la universidad debía tener: "Currículos flexibles. Desarrollar la creatividad frente al pragmatismo imperante. Desarrollar los departamentos con interdisciplinariedad. Utilizar la tecnología para la educación personalizada y para que el profesor tenga más tiempo libre para la investigación" ${ }^{47}$.

Asimismo, los profesores de las universidades europeas, lideradas por la Universidad de Berlín, se reunían para estudiar los mecanismos de unión

45 José Manuel Ríos Ariza y Cebrian de la Serna Manuel, Nuevas tecnologías de la información y la comunicación aplicadas a la educación (Málaga: Ediciones Aljibe, 2000), 18.

46 Robert Dusenbery, Toward the $21^{\text {st }}$ Century in Higher Education. (Corvallis: Oregon State University Press, 1967).

47 Dusenbery, "Toward the", 5. 
de estas instituciones y de esta manera hacerle frente a lo que se pronosticaba que sería la tercera revolución industrial ${ }^{48}$, con efectos en la producción y organización del trabajo, y donde la universidad tendría la obligación social de dar una salida.

No se puede olvidar que para América Latina, en el periodo de los años 1960, la propuesta de una nueva universidad pensada y organizada por un grupo de intelectuales brasileros, bajo el liderazgo de quien fuera el primer rector Darcy Ribeiro (1922-1997) ${ }^{49}$, en la ciudad de Brasilia, se preguntaban ¿si era posible en las naciones subdesarrolladas crear universidades desarrolladas?", y si estas "¿podrían vincular más hondamente la universidad a la nación, haciendo que aquella no solo cumpliera funciones conservadoras, sino que, por el contrario, actuara en forma activamente renovadora?" 50 . Es decir, desde diferentes ámbitos se miraba a la universidad de manera crítica para innovar su currículo y formas de enseñanza ${ }^{51}$.

Unido a lo anterior, se presenta el periodo de la expansión universitaria ${ }^{52}$ en Europa y Estados Unidos y por supuesto América Latina no es ajena a esta nueva situación que se localiza con mayor fuerza especialmente a partir de los setenta, con la matrícula reprimida de la mujer, que logra el acceso, en estos años, a la universidad ${ }^{53}$. Sin lugar a dudas esta situación traía consigo problemas para los cuales el sistema educativo universitario no tenía la respuesta inmediata. Uno de los más evidentes era el de la capacitación docente. El hecho es que en América Latina se pasó de 25.000 estudiantes universitarios en 1960 a 700.000 en 1994 "sin que aumentara simultáneamente la capacidad de formación de los docentes" y esta insuficiencia debilitó su labor pedagógica y la producción investigativa ${ }^{54}$. En Colombia, la tasa de

48 Roberto Rodríguez Gómez, "Universidad y globalización. Contexto, tendencias y desafíos de la educación superior en América Latina”, en Pensamiento Universitario (México: CESU, 1996), 73.

49 En el ańo 1956 inicia su carrera como profesor de Etnología en la Universidad de Brasil, en Rio Janeiro. Javier Ocampo López, "Darcy Riveiro: sus ideas educativas sobre la universidad y el proceso civilizatorio de América Latina", en Revista Historia de la Educación Latinoamericana, No 8, (2006), 137- 160.

50 Ocampo López, “Darcy Riveiro”, 152.

51 Diana Soto Arango, "Criterios comunes para el desarrollo de una educación universitaria global: una propuesta latinoamericana”, en Políticas universitarias en América Latina, tomo II, Colección Historia y prospectiva de la universidad latinoamericana. (São Paulo: Ediciones Doce Calles, 2006), 225-242.

52 Gaston Deurinck, "Introduction" A university of the future. Project 1. "Educating man for the 21th Century, trad. Gaston Deurinck (Bruselas: Martinus Nijhoff, 1974), 188-193.

53 Rosaura Sierra y Gisela Rodríguez, (compiladoras), Feminización de la matrícula de Educación Superior en América Latina y el Caribe (México: Unión de universidades de América Latina, 2005), 14.

54 Galo Burbano López, "La Educación Superior en la segunda mitad del siglo XX. Los alcances del cambio en América Latina y el Caribe”, en Revista Iberoamericana de Educación, Madrid, OEI, (1999), 17. 
escolaridad en educación superior era de las más baja en América Latina, con tan solo el 8,51\%, cuando países como Argentina y Uruguay tenían una cobertura en este nivel del 39 y $42 \%$, respectivamente ${ }^{55}$. Estos hechos hacen pensar en mecanismos para aumentar la cobertura universitaria. Es así que en las políticas gubernamentales, se estableció como mecanismo el apoyarse en la metodología de la educación a distancia, creando la universidad estatal con esta modalidad, con los medios más rudimentarios del momento; las guías escritas, el teléfono, y la televisión educativa, acompañados siempre de las tutorías presenciales de los docentes en cada uno de los lugares ${ }^{56}$.

Por otra parte, debemos indicar que es bien diferente la perspectiva de la tecnología educativa, ubicándola como campo de estudio, que se caracteriza por diseñar y controlar científicamente los procesos de enseñanza ${ }^{57}$.

Debemos reiterar, que con el tiempo, la tecnología y la informática coincidieron en la aplicación en la educación universitaria colombiana. Por todos es conocido que estos campos han evolucionado de tal manera, que el conocimiento de hoy está casi caducado al día siguiente y quizá nuestro medio educativo no avanza al mismo ritmo por los imaginarios y costumbres socioculturales.

En definitiva, los buenos propósitos de las instituciones en la utilización de las tecnologías en el ámbito universitario, se localizaban en: a) mejorar la calidad del aprendizaje, b) ofrecer al estudiantado destrezas cotidianas de la tecnología de la información, que necesitaran en el trabajo y en la vida, c) ampliar el acceso a la educación y a la formación, d) responder al imperativo tecnológico, e) reducir los costos del aprendizaje y, f) mejorar la relación entre costos y eficacia de la enseñanza ${ }^{58}$.

Hay que decir, que las tecnologías digitales ingresan al mercado, prometiendo un nuevo modelo de universidad, con servicios e información constante y actualizada a cada momento, además de agilizar cualquier pro-

55 En la educación superior el panorama era lamentable, con una matrícula total de pregrado y de posgrado de 487.448 estudiantes en 1990 .

56 Diana Soto Arango y Olegario Negrín, "El programa de la UNED de España en Guinea Ecuatorial: una experiencia universitaria en un país del tercer mundo", Revista Vía Abierta, Bogotá, No 5 (1990), 5-15.

57 Manuel Área Moreira, Los medios y las tecnologías en la educación (Madrid: Ediciones Pirámide, 2004), 31.

58 Tony Bates, Cómo gestionar el cambio tecnológico: estrategias para los responsables de los centros universitarios (Barcelona: Gedisa, 2001), 35. 
ceso burocrático ${ }^{59}$. Los resultados se han manifestado en la proliferación de programas on-line, con un impacto sobre la cultura y la educación. Pero en la práctica pareciera que el "mercado educativo" ha sido el que ha primado en la aplicación de las tecnologías, que han permeado los ejes misionales de la universidad, con poca reflexión desde los valores éticos y calidad de la educación superior.

Por otra parte, se indica que "desde la invención de la imprenta, ninguna innovación había ejercido un impacto tan grande sobre la educación, y en especial la educación superior" ${ }^{\prime 00}$.

\section{La investigación e innovación hacia la convergencia digital}

En primera instancia, para acercarnos a una conceptualización de la convergencia digital, es relevante que veamos los orígenes y evolución de su significado junto con un análisis del sujeto social al que va a transformar.

Partiendo de una noción clásica de términos, entenderíamos que "convergencia" significa "unión de dos o más cosas que confluyen en un mismo punto" " ${ }^{\prime}$ y la palabra digital, presenta la relación con el paso de la electrónica analógica a una electrónica digital ${ }^{62}$. Un acercamiento a la conceptualización y características de la convergencia digital, nos llevan a revisar las diferentes tendencias teóricas sobre este aspecto.

Meir Finkel, desde la visión empresarial, concibe la convergencia digital como: "el conjunto de innovaciones tecnológicas y transformaciones políticas, sociales, económicas y culturales que caminan hacia la unificación de medios de captura, almacenamiento, actualización, transformación, transmisión, distribución, consulta y venta de la información procedente de múltiples fuentes, dispositivos y aparatos eléctricos"63.

59 Sergio Ortega Santamaría, "La nueva e-universidad. Estrategias de comunicación en los portales universitarios", Revista Académica del Foro Iberoamericano sobre Estrategias de Comunicación. Año III, No 6, Mesa III (2007), 19-34.

60 Susana Finquelievich y Alejandro Prince, Universidades y TICs en Argentina. Las universidades argentinas en la sociedad del conocimiento. (2005), http://www.scribd.com/doc/4940962/Finquelievich-y-Prince Las-Universidades-Argentinas-en-la (20 de noviembre de 2011).

${ }_{61}$ www.wordreference.com, "convergencia". http://www.wordreference.com/definicion/convergencia(27 de Febrero de 2012).

62 La electrónica analógica utiliza "señales eléctricas que varían de forma continua y variable" para representar y transmitir información. La electrónica digital utiliza "señales eléctricas que pueden tomar valores finitos, normalmente el 0 y 1” (bajo o alto). Con base en José Roldán Viloria, Automatismos y cuadros eléctricos (Madrid: Editorial Paraninfo, 2004), 203.

63 Meir Finkel, Convergencia digital, http://www.slideshare.net/meirfinkel/convergencia-digital (12 de Febrero de 2012). 
Por otra parte, Alfonso Vázquez Atochero la establece desde lo que él denomina iberantropología. Por lo tanto, con una visión humanista donde la técnica se aplica para el bienestar humano, nos indica que "La convergencia digital va encaminada a recoger todas las funcionalidades desarrolladas por la industria tecnológica en las últimas décadas, en aparatos cada vez más sofisticados y en un breve espacio de tiempo ofrecerá soluciones menos complejas, más humana" ${ }^{64}$. Quizás, otra posición más instrumentalista señala que "la convergencia digital representa la posibilidad de acceder a distintos medios y tecnologías a través de un único aparato" ${ }^{65}$. Pero, Cindy F. Salomon nos plantea, desde los resultados que afectan el trabajo del hombre, al señalar que "la convergencia digital sustancialmente afecta nuestro estilo de vida personal y estilo de trabajo. Transforma las telecomunicaciones, informática, internet, medios de comunicación, electrónica y las industrias de servicios de creación de nuevos ecosistemas y cadenas de valor" ${ }^{\prime 66}$.

\subsection{Gráfico 1. Convergencia digital}

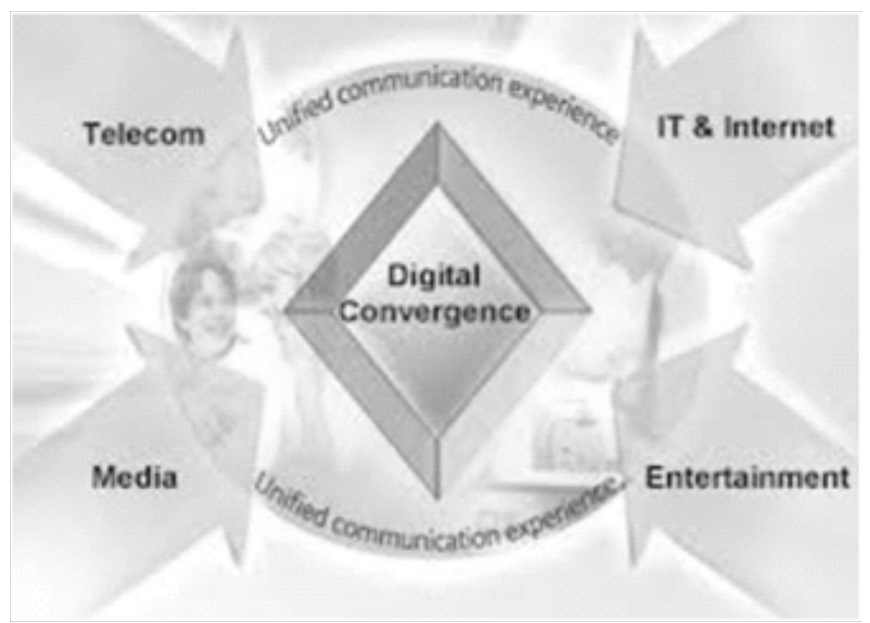

Fuente: Harry Strasser. Digital convergence, http://www.digitalconvergence.eu/ (10 de febrero de 2012).

64 Alfonso Vázquez Atochero, Ciberantropología: cultura 2.0 (Barcelona: Editorial UOC, 2008), 25.

65 Los Hermenéuticos Cgp, Convergencia digital: una unión de conocimientos tecnológicos, http://hermeneuticoscgp. blogspot.com/2011/03/convergencia-digital-una-union-de.html (17 de enero de 2012).

${ }_{66}$ [Mitraducción] original en inglés "Digital Convergence substantially impacts our personal lifestyle and work style! It transforms Telecommunication, IT, Internet, Media, Electronics and Services industries creating new ecosystems and value chains". Cindy F. Salomon. WhatIs Digital Convergence? (2010) http://www.slideshare. net/CFSolomon/what-is-digital-convergence(10 de febrero de 2012). 
Otros, como Harry Strasser, lo ven en las aplicaciones para la comunicación y por este motivo centran la conceptualización en que las telecomunicaciones, internet, medios, electrónica y servicios ${ }^{67}$. La convergencia digital se caracteriza por la escritura digital, hipertexto, aplicaciones multimedia, hipermedia, ciberespacio, medios masivos, e-learning ${ }^{68}$ y "el deseo humano de estar conectado con otros" ${ }^{\prime 69}$.

Es así que la convergencia digital tiene un punto de encuentro, en los teóricos que analizan el tema, al indicar el uso variado de los medios informáticos. Sin embargo, existe diferencia en el uso que se da a los mismos. Otras voces, desde un punto de vista crítico, señalan que la convergencia digital es una moda más, producto del marketing y la sociedad de consumo. Por lo que responden los seguidores de la innovación tecnológica, que el uso de tecnologías digitales es actualmente una necesidad y hace parte de la cotidianidad de los usuarios que hacen (o hacemos) parte de la sociedad de la información y el conocimiento.

Por nuestra parte, consideramos que la convergencia digital es entendida como una mezcla y unificación de innovaciones tecnológicas (en uno o varios dispositivos) que permiten almacenar y acceder a múltiples medios de información, con un potencial de cambio e innovación. Lo relevante para el campo educativo universitario es que se mira desde el principio de la ética y valores ciudadanos. Consideramos que son estos los que van a permitir la transformación de los procesos de enseñanza y aprendizaje y la construcción de conocimiento, desde competencias ${ }^{70}$ comunicativas diferentes. Precisamente, la cobertura estudiantil, por medio de la educación virtual, presenta situaciones problémicas individuales que deben ser atendidas para lograr las metas de una sociedad más equitativa e igualitaria, incluyendo el principio de la unidad de hombres y mujeres en la diferencia y complementariedad solidarias.

Pero, se debe tener en cuenta que la aplicación de esta convergencia digital se realiza en un sujeto social, que es transformado en valores cul-

${ }_{67}$ Harry Strasser. Digital convergence, http://www.digitalconvergence.eu/ (10 de febrero de 2012).

68 Meir Finkel.Convergencia digital (2010), http://www.authorstream.com/Presentation/meirfinkel-330259-convergencia-digital-new-tecnology-education-ppt-powerpoint/ (20 de febrero de 2012).

69) Planning De Ogilvy Latina, ¿Cómo vivimos la convergencia digital de hoy? (2006) http://www.laflecha.net/canales/comunicacion/noticias/200607211 (27 de febrero de 2012).

70 Las competencias fueron analizadas ampliamente en el Programa 6X4. Diana Soto Arango, "La investigación y la innovación en los programas de Historia y Ciencias Sociales en Colombia. Una propuesta desde el Proyecto 6X4", en Revista Historia de la Educación Latinoamericana, Tunja, N 9, (2007), 203-230. 
turales, donde se dan procesos de desaprender para volver a aprender. Quizás, una de las grandes transformaciones, que evidencia un cambio de comportamiento, es el paso de la lectura en soporte impreso a formato electrónico. Sin lugar a dudas, esta situación conlleva a una motivación por el uso del computador o los dispositivos móviles en la cotidianidad y por supuesto una gran ruptura frente a la tradición del libro impreso, resguardado, estudiado y coleccionado con un gran valor de afectividad ${ }^{71}$.

Otro aspecto, de transformación de este sujeto social, es el referente al hecho que la cultura de las mediaciones complejas a través de los medios masivos (radio, prensa, televisión, cine, hipermedia adaptativa ${ }^{72}$, videojuegos y otros), transforman una realidad. De esta manera, "la masa es convertida en público y las creencias en opinión que casi que conducen la vida por un mundo de ilusión, mitología y magia"73.

De igual manera, debemos señalar, la construcción colectiva del conocimiento a través del uso del internet. Este, ya no puede ser considerado como un instrumento de un simple repositorio estático de información, sino un punto de encuentro donde convergen grupos (sujetos sociales con un interés común), y son los propios usuarios los que colaboran e interaccionan entre sí, para generar la información. Esta visión colectiva del conocimiento está ligada al desarrollo de aplicaciones que residen en internet y a la gratuidad de su uso, que es lo que les da la oportunidad a las personas excluidas, al acceso y uso de las TIC, un tipo de brecha económica.

Otro aspecto, está unido al mercado que se ha desarrollado a través de las TIC. La realidad es que el sujeto se encuentra inmerso entre una cultura y la contracultura de la convergencia tecnológica. Como ejemplo, a inicios de los años setenta los programas de computador, fueron vistos como un factor de ingresos a futuro y las empresas comenzaron a vender el software como valor agregado. Es así, como las universidades dejan de recibir el código fuente que estudiaban sus grupos de investigadores y es

${ }^{71}$ Los trabajos de Roger Chartier sobre la historia de la lectura. Ver en especial las siguientes obras en español: Historia de la lectura en el mundo occidental (Madrid: Taurus, 1998); Libros, lecturas y lectores en la edad moderna (Madrid: Alianza, 1993); El mundo como representación: estudios sobre historia cultural (Barcelona: Gedisa, 1995); Cultura escrita, literatura e historia: coacciones trasgredidas y libertades restringidas, conversaciones de Roger Chartier (México: FCE, 1999).

72 La posibilidad de adaptar en la misma interfaz gráfica de usuario, elementos multimediales.

73 Jesús Martín. Barbero, De los Medios a las Mediaciones, comunicación cultura y hegemonía (Barcelona: Anthropos Editorial, 2010), 31. 
tudiantes, porque los autores del software le percibían la posibilidad de negocio. De esta manera, aparece el concepto de software propietario, donde el autor cobra un precio por su uso (licencias), siendo el único autorizado para modificar los programas, (siempre y cuando sea rentable).

Como es bien conocido, lo anterior, trajo como consecuencias el cambio de plataforma y optimización de los sistemas, que ocasiona barreras económicas y de acceso al conocimiento a ciertas culturas. Los usuarios que no pueden adquirir estos programas, buscan estrategias para contrarrestar la problemática, un ejemplo es el movimiento del software libre (la contracultura), que promulga por una libertad de los usuarios para copiar, ejecutar, distribuir, estudiar, cambiar y mejorar el software, adaptándolo a sus necesidades.

Finalmente, establecido el concepto, un segundo aspecto a tener en cuenta en la convergencia digital es, sin lugar a dudas, el progreso de la electrónica que permitió a la par el avance de la informática. Este último, término, se acuñó en Francia en 1962 como contracción de las palabras información y automática ${ }^{74}$. Debemos indicar, que originalmente, significaba la realización de tareas por medio de máquinas (autómatas) y que ahora es entendida como la "ciencia que trata de la concepción, realización y utilización de los sistemas o estructuras que procesan la información" 75 .

Posteriormente, las telecomunicaciones ${ }^{76}$, que se pueden definir como "comunicación a distancia", hacen referencia al envío bidireccional de mensajes, lo que incluye a tecnologías que han avanzado desde la telegrafía, a la radio, telefonía, televisión, transmisión de datos a través de computadores, unido a los adelantos en satélites de comunicación, fibra óptica e internet, entre otros. Por otro lado, la comunicación se define "como la impartición, envío o intercambio de información entre diferentes entidades" 77 , por lo tanto, la aparición de las telecomunicaciones, en especial internet, ha propi-

\footnotetext{
74 Carmen De Pablos Heredero, et al., Informática y comunicaciones en la empresa (Madrid: ESIC Editorial, 2004), 14.

75 Miguel Hernández González y José Luis Prieto Pérez, Historia de la Ciencia, Vol. II (Tenerife: Fundación Canaria Orotava, 2007), 245.

76 Palabra compuesta por dos vocablos: uno de origen griego, tele, que significa lejano o a distancia y otro de origen latino communicatio, que significa comunicación o poner en común. Antonio Ricardo Castro Lechtaler y Rubén Jorge Fusario. Teleinformática para ingenieros en sistemas de información (Barcelona: Editorial REVERTE 1999), 598.

77 Enrique Herrera Pérez, Introducción a las telecomunicaciones modernas (México: Editorial Limusa, 2004), 21.
} 
ciado nuevas formas de transmitir, divulgar e informar y que ha transformado la cotidianidad de la población.

Para la Unión Internacional de Telecomunicaciones (UIT) en un congreso internacional celebrado en Madrid en el año 1932, define la telecomunicación como "toda transmisión, emisión o recepción de signos, señales, escritos, imágenes, sonidos o informaciones de cualquier naturaleza por hilo, radioelectricidad, medios ópticos u otros sistemas electromagnéticos" ${ }^{\text {78 }}$. Actualmente, dentro de los usos de comunicación a distancia, se encuentran la transmisión de datos, voz, imágenes y vídeo.

Podríamos concluir que estos avances permiten digitalizar cualquier tipo de información, prestar servicios, conectar en red y para este caso, apoyar los procesos educativos en las instituciones universitarias.

\section{Experiencias de convergencia digital}

Para el desarrollo del mundo digital, en el contexto universitario, partimos de la premisa que toda la sociedad está inmersa en información, que genera y transmite por cualquier proceso que realice. Por ende, los cambios o innovación en los sistemas que se utilizan para organizarla, almacenarla, enviarla y recibirla, hacen parte de la convergencia digital. Sin embargo, la manera de acceder a la misma se realiza de dos formas: la formal y acorde al mundo globalizado, representado en la cultura; y los excluidos de esta que buscan la manera de acceder al uso de las tecnologías.

En cuanto a las investigaciones, que evidencian el interés del saber científico por generar escenarios de convergencia digital en el contexto universitario, localizamos algunas instituciones líderes en el acompañamiento de comunidades, que deben ser incluidas en los avances del desarrollo tecnológico. A continuación analizamos nueve experiencias de investigación en universidades iberoamericanas.

La primera, desde un contexto internacional, se planteó desde varias universidades españolas, el proyecto "Campus para la Convergencia Digital CONDICAMPUS”, presentado por la Universidad de Alcalá de Hena-

78 Aníbal Raúl Figueiras Vidal, Una panorámica de las telecomunicaciones (Madrid: Pearson Educación, 2002), 31 . 
res, Universidad Nacional de Educación a Distancia (UNED) y el Centro Superior para la Enseñanza Virtual (CSEV). Esta propuesta tenía como objetivo la modernización e internacionalización de estas universidades. El proyecto, se fundamentó en tres ejes: "la información y el conocimiento en la sociedad en red con la creación de un centro para el análisis de la cultura digital, el español en la intercomunicación digital y como lengua de cultura, pero también como lengua de la ciencia y la ejecución de programas, que consideró la población, entorno y ciudadanía en la sociedad global"79. Se evidencia con esta experiencia el propósito de las universidades por emprender proyectos de innovación en las actividades de investigación y formación.

La segunda experiencia, presenta un trabajo innovador sobre convergencia digital y educación, sobre algunas investigaciones y trabajos realizados por universidades para entornos educativos en e-learning y su especificidad m-learning, donde se evidencian procesos de cambio hacia la convergencia digital. Merece especial mención la que se sustenta en ontologías $^{80}$ de los laboratorios virtuales en las ingenierías en informática" ${ }^{81}$. Este trabajo muestra el proceso de creación de Laboratorios Virtuales, que consistió en diseñar, una estructura y una caracterización de los laboratorios convencionales; luego realiza una especificación formal basada en ontologías, y finalmente los crea sobre una plataforma real de aprendizaje. El principio es el de innovar a través de la unificación de medios en la Web (laboratorios virtuales), como un cambio en los ambientes de aprendizaje tradicionales, en la búsqueda de optimizar recursos y procesos educativos y de esta manera establecer la relación de la convergencia digital.

Una tercera investigación, producto de una tesis doctoral en la Universidad de Oberta, Cataluña, es la referente a la "Tecnología, economía y universidad: análisis de los efectos de las tecnologías de la información y la comunicación sobre la eficiencia económica de las universidades

79 www.rtve.es/, UNED - Campus para la convergencia digital CONDICAMPUS (2011), http://www.rtve. es/alacarta/videos/uned/uned-campus-para-convergencia-digital-condicampus-04-11-11/1240657/ (27 de febrero de 2012).

80 "Las ontologías son un medio para representar las construcciones mentales (abstracciones) creadas por un ser humano” José María Cavero Barca, Belén Vela Sánchez, Esperanza Marcos Martínez, Aspectos filosóficos, psicológicos y metodológicos de la informática (Madrid: Librería-Editorial Dykinson, 2005), 103.

$81 \quad J o s e p$ Prieto Blázquez, "Caracterización y especificación basada en ontologías de los laboratorios virtuales en las ingenierías en informática”. (Tesis de doctorado en la Universidad Oberta de Cataluña, 2008) http://openaccess.uoc.edu/webapps/o2/bitstream/10609/1474/1/tesi_jprieto.pdf(11 de octubre de 2010). 
virtuales".82. En este caso, estudia el proceso de transformación de las universidades de los países miembros de la Organización para la Cooperación y Desarrollo Económicos (OCDE), durante las dos últimas décadas, en concreto los parámetros de su evolución hacia el concepto de universidad red y su interacción con la adopción y difusión del uso de las TIC en la actividad docente y en la gestión universitaria. Los resultados en la relación de la convergencia digital están dados por la modalidad e-learning, como una alteración metodológica y de costos, que difiere de las estructuras tradicionales implantadas en el sector universitario.

Una cuarta experiencia, es "La concepción didáctica del docente y los materiales didácticos digitales: voz, texto y producción de profesores universitarios" que se realizó en México ${ }^{83}$. Allí, se buscó comprender desde la perspectiva del docente, cómo y por qué se insertan las tecnologías digitales en la docencia universitaria, específicamente a través del estudio del diseño y creación de materiales didácticos digitales. Los hallazgos del estudio amplían el conocimiento sobre los elementos y dinámicas de inserción de la tecnología en el aula, superan visiones parciales y establecen una estructura para la reflexión de los docentes sobre la articulación de sus creencias didácticas y las posibilidades que las TIC ofrecen. Se evidenciaron cambios culturales en la forma del trabajo del docente, generando nuevas actitudes hacia el uso de las tecnologías digitales.

Una quinta experiencia, es la que incorporó la tecnología móvil en la educación primaria, desarrollado en la Universidad Metropolitana de México. Se implementaron unos $\mathrm{PDA}^{84}$ para observar su uso y aceptación, con contenidos de acuerdo a la intensidad horaria de las asignaturas del plan de estudio. Los objetivos en el área de español fueron desarrollar las capacidades de comunicación de los niños, en los distintos usos de la lengua hablada y escrita; en matemáticas era razonar y comprender los textos para resolver problemas y aprender a vincular su conocimiento con el mundo que lo rodea.

82 David Castillo i Merino, "Tecnología, economía y universidad: análisis de los efectos de las tecnologías de la información y la comunicación sobre la eficiencia económica de las universidades virtuales". (Tesis de doctorado en la Universidad Oberta de Cataluńa, 2004) http://www.tdx.cat/bitstream/handle/10803/9116/Tesi_dcastillo. pdf?sequence=1 (13 de Octubre de 2010).

83 Alma Beatriz Rivera Aguilera, "La concepción didáctica del docente y los materiales didácticos digitales: voz, texto y producción de profesores universitarios” (1981). www.bib.uia.mx/tesis/pdfl015230/015230.pdf(10 de noviembre de 2010).

84 Dispositivo de pequeño tamaño que combina un ordenador, teléfono/fax, internet y conexiones de red 
La sexta experiencia, "Telefonía celular aplicada a la educación con TIC" desarrollado ${ }^{85}$ en 2008, en Zamora, Buenos Aires, Argentina. El objetivo del proyecto fue estudiar el uso de los celulares como recurso educativo. Las conclusiones muestran que el manejo apropiado de la tecnología móvil, posee un alto grado de creatividad e innovación, acordes a los parámetros sociales del siglo XXI. Aunque estas investigaciones son para contextos no universitarios, se observa la adaptación y uso de dispositivos en los que confluyen distintos medios, con el fin de influir en forma positiva en los procesos educativos.

La séptima experiencia que seleccionamos, se realizó en Venezuela, con el uso de la tecnología celular como medio de comunicación masivo" Observó el comportamiento del estudiante en el uso del celular y buscó determinar normas y restricciones para su uso adecuado, con base en el siguiente problema: "El uso masivo de la tecnología móvil en fotografías y videos pornográficos, tomados por los estudiantes, generaron polémicas en los docentes, en el uso del celular dentro de las instituciones educativas debido a que también crea distracción que dispersa la atención en clase de los estudiantes". Demuestra que la convergencia de tecnologías también genera inconvenientes, en los cuales se debe profundizar a través de la investigación científica.

La octava experiencia se tomó de la Universidad Nacional de Colombia. "Modelo de identificación de locutor en entornos, Sistema Global de Comunicación Móvil (GSM), y su aplicación en Colombia". Este estudio planteó implementar las TIC, a través de una emisora y por vía teléfono celular, a través de un locutor y/o el docente que ayudaba con la difusión de las temáticas de libros digitales, dirigidos a la Escuela Carlos Arcila Vásquez, (vereda del Dragal, municipio de Argelia, Antioquia), para dar solución a los estudiantes que no cuentan con recursos bibliográficos suficientes. El autor concluyó que es posible mejorar el nivel académico de los alumnos del centro educativo, que se verán retribuidos en el contexto social, en el cual los alumnos están trabajando y desarrollan sus actividades

85 Ana María Sánchez, "Telefonía celular aplicada a educación-nuevas TIC” (2008) http://portal.educ.ar/debates/ educacionytic/debate/post-7.php (15 de marzo de 2011).

86 Anthony Barreto, Luis Arias y Jorge Petit, "Uso de la tecnología celular como medio de comunicación masivo" (2008) http://www.monografias.com/trabajos62/telefonia-celular-medio-comunicacion-masivo/telefonia-celular-medio-comunicacion-masivo2.shtml (20 de junio de 2011). 
cotidianas ${ }^{87}$. Compila diversos medios para transformar hábitos de estudio adaptados a comunidades educativas.

Destacamos por su entidad, una novena experiencia que se desarrolló en el ámbito nacional colombiano, bajo un proyecto de investigación con los criterios requeridos para la construcción de escenarios educativos virtuales, como una convergencia de los escenarios tradicionales, sobre la base de mediaciones tecnológicas ${ }^{88}$. Resultado de este primer experimento de aprendizaje en ambientes colaborativos y cooperativos virtuales, se consiguió propiciar espacios en los cuales se dio el desarrollo de habilidades individuales y grupales, a la hora de desarrollar un nuevo aprendizaje. De especial relevancia fue el hecho de haber logrado la participación de estudiantes ubicados en diferentes regiones de Colombia. En este caso, cada estudiante fue responsable de su aprendizaje, pero a su vez lo era de los demás miembros del grupo. En los resultados de la investigación se demostró, cómo la convergencia digital y su aplicación permitió cambios en los procesos de aprendizaje, destacándose el colectivo. Es más, se indica en estos resultados que con la utilización de los ambientes virtuales (medio de convergencia e innovación de los procesos educativos), se logró reducir el aislamiento del estudiante (mayor inconveniente del modelo de educación a distancia) y se activó los procesos de aprendizaje autodirigido y autónomo (actúan como modelos pedagógicos que coadyuvan al desarrollo de ambientes virtuales educativos), donde trasciende la dinámica individual y se proyecta el trabajo grupal colaborativo y se establece el aprendizaje basado en lo conjetural.

Giovanni Medina Alfaro ${ }^{89}$, nos indica que las grillas computacionales ${ }^{90}$ poseen las mismas ventajas que los sistemas distribuidos como lo son tolerancia a fallos, compartir recursos, procesamiento paralelo, etc. Lo que

87 Elkin Ramón Garavito Neira, "Modelo de Identificación de Locutor en Entornos GMS, Aplicación"(2010) http:// www.bdigital.unal.edu.co/3149/1/299634.2010.pdf (10 de agosto de 2011).

88 Carlos Andrés Pérez, "Herramientas computacionales para la generación de Multimedia Educativa”, Revista TEA (Tecne, Episteme, Didaxis). Universidad Pedagógica Nacional, vol. 3 fasc: 6 (2005), 20-26.

89 Oscar Giovanni Medina Alfaro, El estado del Arte del Grid (2011). http://www.google.com.co/url?sa=t\&rct=j\& $\mathrm{q}=$ Investigaciones+sobre+la+grilla + computacional \&source=web\&cd $=8 \& \mathrm{cad}=\mathrm{rja} \& \mathrm{ved}=0 \mathrm{CGIQFjAH} \& u \mathrm{ul}=\mathrm{htt}$ p\%3A\%2F\%2Fpegasus.javeriana.edu.co\%2F $\sim$ CIS1010SD01\%2Farchivos\%2FAnexo2.docx\&ei=ydwaUbWk JYGc2QXI3YDQAw\&usg=AFQjCNHgJnJm-8nJWW8kjO7tk7RdqAN4Jw

90 La grilla computacional es: "Aplicación de recursos computacionales de varias computadoras en la red para un problema único, grande y complejo". Kenneth CLaudon y Jane Price Laudon, Sistemas de información gerencial: administración de la empresa (México: Pearson Educación, 2004), 192. 
lo hace diferente a los sistemas distribuidos es que tales características, se encuentran en un nivel de múltiples instituciones, permitiendo así controlar la gestión de los recursos distribuidos geográficamente. Este estudio evidenció que las grillas computacionales pueden transformar hábitos de trabajo, que benefician los procesos de investigación y los servicios de gestión de la información en las universidades.

En definitiva, en estas nueve experiencias, más el estado del arte, se muestra como los sistemas de la universidad, ambientes de aprendizaje, modelos y metodologías, actitudes y hábitos educativos tradicionales, migran a sistemas digitales con innovaciones en electrónica, telecomunicaciones y/o software, que permiten avanzar hacia cambios que optimizan y digitalizan información, y de esta forma amplían la cobertura e ingresan en la economía del conocimiento.

Asimismo, las investigaciones evidenciaron el interés del saber científico, en el contexto universitario, por generar escenarios de convergencia digital. Consideramos, que estas instituciones se ubican como líderes del acompañamiento y de la innovación en el proceso de enseñanza y aprendizaje con soporte en tecnologías digitales.

Igualmente, se puede concluir, que en algunas universidades ${ }^{91}$ se destacan proyectos y alianzas en distintos países, para compartir recursos de aprendizaje, campus y comunidades virtuales, formación personalizada, gestión del conocimiento $^{92}$, junto a la creación constante de servicios innovadores, que buscan colocar a las instituciones a la vanguardia del liderazgo tecnológico y añadir valor a las actividades docentes, de investigación y de gestión.

Otras acciones son el fomento del software libre ${ }^{93}$, los sistemas abiertos ${ }^{94}$, el trabajo con diversas plataformas tecnológicas, la creación de labo-

91 La siguiente información tomó como base a la Universidad Oberta de Cataluña, institución que se destaca a nivel mundial por su modelo y el uso de las TIC en la educación.

92 "Conjunto de técnicas, herramientas y prácticas que persigue la creación, distribución y almacenamiento y aplicación del conocimiento tanto en el seno de una empresa, como dentro de una red de empresas" Joaquín Alegre Vidal, La gestión del conocimiento como motor de la innovación: lecciones de la industria de alta tecnología para la empresa (Castellón de la Plana: Universitat Jaume I, 2004), 48.

93 "Es aquel software, producto o desarrollo a medida, que se distribuye bajo una licencia, según la cual el autor cede una serie de libertades básicas al usuario en el marco de un acuerdo de concesión”. José Ángel Martínez Usero y Pablo Lara Navarra, La producción de contenidos web (Barcelona: Editorial UOC, 2007), 15.

94 "Lo que significa que se diseñan sobre protocolos estándar que permiten combinar equipamiento y software de diferentes vendedores", María Isabel Alfonso Galipienso, Ingeniería del software. Séptima edición (Madrid: Pearson Educación, 2005), 242. 
ratorios de innovación con desarrollos en contenidos y asignaturas adaptables para diferentes dispositivos y soportes electrónicos (MP3 ${ }^{95}$, libro electrónico, audio libro y vídeo libro), además de proyectos de realidad virtual ${ }^{96}$ y realidad aumentada ${ }^{97}$, para ser más accesible, flexible y proyectarse socialmente con los servicios de formación académica para diferentes usuarios dispersos por el mundo. En definitiva, lo anterior demuestra el camino recorrido por la universidad hacia la convergencia tecnológica y de medios.

\section{Una aproximación a la evolución de la convergencia digital en el contexto colombiano}

Para entender la utilización de las TIC en las universidades colombianas debemos partir de la educación a distancia, enmarcada en el hecho histórico cuando se aplicaron los medios de comunicación social y las tecnologías de la información a la enseñanza. Ya en el año 1982, con el decreto 2412, se establecía el Consejo de Educación Abierta y a Distancia ${ }^{98}$, dependiendo directamente de la Presidencia de la República. No había pasado un año cuando vuelve a reglamentarse esta modalidad en la parte conceptual y se establece que se tendrán sesiones presenciales ${ }^{99}$. El apoyo gubernamental fue total a la nueva modalidad educativa que instaura espacios gubernamentales, de radio y televisión, para los programas de educación abierta y a distancia ${ }^{100}$. Pero debemos indicar que la Universidad de Antioquia, desde 1974, ya había implementado lo que esta institución denominaba la Universidad Desescolarizada ${ }^{101}$. Sustentados en la legislación

95 Es un formato de sonido, (MPEG audio layer III), que es el formato comprimido (de) calidad casi de CD”. Sara Osuna Acedo y Carlos Busón Buesa, Convergencias de medios: la integración tecnológica en la era digital (Barcelona: Icaria Editorial, 2008), 157.

96 "Es la manipulación de los sentidos humanos (tacto, visión y audición) por medio de entornos tridimensionales sintetizados por computadora en el que uno o varios participantes acoplados de manera adecuada al sistema de computación interactúan de manera rápida e intuitiva, dejando como real el entorno generado por la computadora”. Enrique Ruiz Velasco Sánchez, Educatrónica: Innovación en el aprendizaje de las ciencias y la tecnología (México: Ediciones Díaz de Santos, 2007), 12.

97 "Consiste en añadir gráficos virtuales, en tiempo real, al campo de visión de una persona. Su finalidad es superponer al entorno real la información que interesa visualizar”, Begońa Gros et al., Videojuegos y aprendizaje (Barcelona: Grao, 2008), 143.

98 El decreto 2412 de agosto 19 de 1982 reglamenta la educación abierta y a distancia en Colombia y la define en el artículo 1, como "el conjunto de actividades y programas de carácter temporal o permanente, formal y no formal, que adelanten las instituciones facultades para ello por las autoridades estatales competentes, de acuerdo con planes de formación o capacitación, total o parcialmente desescolarizados”.

99 Decreto 1820 de junio 28 de 1983 , artículo 2.

100 Decreto-Ley 22 de 1983, artículo 26.

101 Resolución Rectoral 857 del 10 de septiembre de 1974. Se establecía en esta modalidad hasta 12 créditos. Un curso tenía un valor de 200 pesos, dos cursos ( 8 créditos) 350 pesos, tres cursos (12 créditos) 500 pesos. 
vigente, las primeras universidades colombianas con programas a distancia se apoyaron en la utilización de la correspondencia, los módulos en papel, la T.V., el teléfono, sin abandonar la tutoría presencial, como lo realizaba la UNED en España, que fue uno de los modelos aplicados en la primera universidad estatal a distancia en Colombia ${ }^{102}$.

Podemos decir, que la expansión de esta modalidad educativa superó los límites esperados. Quizás, haya incidido de manera contundente el hecho que el decreto 2277, de 1979, establecía "como obligatoriedad la modalidad de educación a distancia como uno de los mecanismos de capacitación del magisterio colombiano" (art. 45). El boom de la capacitación docente se puso a la orden del día. Aún hoy, tenemos universidades que siendo presenciales han triplicado los estudiantes en la modalidad a distancia $^{103}$. Por supuesto, debemos señalar igualmente que algunas universidades han tratado de dar el paso a la educación virtual, dejando atrás las "sesiones presenciales". En estos casos, como en Boyacá, la matrícula disminuyó totalmente en la modalidad a distancia ${ }^{104}$. Lo anterior, nos lleva a concluir que el paso a la educación virtual conlleva unos cambios socioculturales en algunas regiones del país.

Precisamente, la tesis doctoral de Edith González ${ }^{105}$, nos da algunas de las respuestas en el recorrido histórico de la educación a distancia en las universidades colombianas. La autora se pregunta sobre ¿Qué modelos pedagógicos han orientado la formación del tutor para la educación a distancia y los ambientes virtuales del aprendizaje en las universidades Javeriana y Antioquia durante el período 1974-2002? ${ }^{106}$. En la investigación, diferencia tres momentos: el primero, caracterizado por módulos escritos, correo convencional, teléfono y televisión. El segundo, con mediaciones tecnológicas (hipermedia); y el tercero con el uso de internet y plataformas educativas, lo que indica el uso de medios tecnológicos en los últimos años. Es relevante que concluye que para implementar los ambientes virtuales

102 Diana Soto Arango y Olegario Negrín. "El programa de la UNED de España en Guinea Ecuatorial. Una experiencia universitaria en un país del tercer mundo", 5-15.

103 Por ejemplo la universidad del Tolima, en el año 2012 presentaba 12 estudiantes presenciales y 42.000 mil a distancia.

104 Podemos indicar el caso de la Universidad Pedagógica y Tecnológica de Colombia, en el año 2010.

105 Edith González Bernal, "Formación del tutor: para la educación a distancia y los ambientes virtuales de aprendizaje en la Universidad Colombiana, 1974-2002” (Pontificia Universidad Javeriana, 2006), 16.

106 Edith González Bernal, "Formación del tutor: para la educación a distancia y los ambientes virtuales de aprendizaje en la Universidad Colombiana, 1974-2002”, 18. 
en el aprendizaje, se debe posicionar la calidad, la apertura y la flexibilidad. En otro estudio realizado por Carlos Patiño, considera que

Las instituciones de educación superior, por su parte, no todas han experimentado el proceso de convergencia en un mismo lapso de tiempo la heterogeneidad y complejidad de éstas han incorporado dichos cambios tecnológicos y cientificos en temporalidades diferentes, esta desigualdad ha generado problemas de calidad y pertinencia en los niveles de pregrado y postgrado que inciden en la capacidad investigativa del pais ${ }^{107}$.

A lo anterior se suma que las innovaciones tecnológicas tardan en apropiarse en los procesos educativos. El informe de avance del primer semestre de 2007 del Programa de Uso de Medios y Nuevas Tecnologías de Información y Comunicaciones, reveló que en las instituciones de educación superior colombianas se presentaba un alto nivel de acceso a computadores e internet. Asimismo, la educación virtual, hacía presencia a través de la banda ancha, la implementación de la Televisión Digital Terrestre (TDT), esta última con sus ventajas multicanal, recepción en dispositivos móviles o portátiles e interactividad con el contenido ${ }^{108}$.

Igualmente, debemos indicar que algunas universidades vienen creando algunos escenarios de convergencia digital, mediante contenidos virtuales abiertos, participación en el Banco Nacional de Objetos de Aprendizaje y la vinculación a redes regionales y a través de estas a la Red Nacional de Tecnología Avanzada (RENATA), para acceder a servicios como la transmisión de eventos. Otros casos son la implementación de emisoras radiales universitarias (56 en el país a marzo de 2013), algunas de las cuales se pueden escuchar on-line, y la participación en el canal universitario de Televisión "Zoom”.

Otra forma, que se utiliza en las universidades colombianas es el canal universitario en internet. Una experiencia reconocida es el Canal "Prisma Tv" de la Universidad Nacional de Colombia. Algunas se proyectan más allá, ejemplo de ello es el "Centro Ático" en la Pontificia Universidad Javeriana, el cual plantea

107 Carlos Patiño Millán, "Apuntes para una historia de la educación en Colombia". http://www.scribd.com/ doc/35036644/APUNTES-PARA-UNA-HISTORIA-DE-LA-EDUCACION-EN-COLOMBIA (20 de noviembre de 2011).

108 Ministerio de Educación Nacional, "Informe de Avance Primer Semestre 2007. Programa de uso de medios y nuevas tecnologías de información y comunicaciones" (2007) http://www.colombiaaprende.edu.co/html/mediate$\mathrm{ca} / 1607 /$ article-167890.html(21 de Noviembre de 2001). 
apoyar a las unidades académicas y entes externos en la formación, investigación y desarrollo de proyectos de imagen (cine, video, televisión, diseño digital y arte electrónico), audio y acústica (radio y sonido), educación asistida por Tecnologías de Información y Comunicación, asesorando y estimulando la creación, experimentación, innovación y realización de propuestas ${ }^{109}$.

Otras instituciones universitarias cuentan con páginas Web, que incluyen múltiples servicios en línea (más administrativos que académicos), y cuentan con redes sociales, que demuestran el crecimiento de un entorno digitalizado en servicios y contenidos, concentrados principalmente en internet, con el propósito de estar disponibles por medio de dispositivos móviles. Es más, esta visibilidad es medida a través de los resultados del Ranking Web de Universidades del mundo: Webometrics ${ }^{110}$, emitidos por el Laboratorio de Cibermetría, que pertenece al Consejo Superior de Investigaciones Científicas de España. CSIC, mayor centro nacional de investigación de España. En estas mediciones la visibilidad corresponde a un nuevo indicador llamado Impacto, este tiene un valor del $50 \%$ en el cálculo del ranking y se refiere a la cantidad de enlaces entrantes (inlinks) al sitio Web de las universidades.

En lo referente a los estudiantes universitarios colombianos denominados Nativos Digitales ${ }^{111}$, mantienen la necesidad de comunicarse e interactuar por estos medios, algunos con fines de entretenimiento (escuchar o descargar música, redes sociales, y otros hobbies.). Por lo tanto, la pregunta que hacemos a las universidades es de ¿Cuáles son las expectativas y qué puede ofrecer en experiencias educativas novedosas la convergencia digital a estos usuarios digitales? Desde la formulación del CONPES 3072, en el año 2000, el Estado viene buscando un contexto propicio para la apropiación de las TIC, que para 2011 se encuentra con un importante rezago en la utilización del internet y de computadores, frente a otros países de la región ${ }^{112}$.

Por otra parte, de acuerdo con lo señalado en este trabajo, se plantean dos escenarios, que desde el contexto de las universidades permitirán avan-

109 Centro Ático. "Razón de ser” http://puj-portal.javeriana.edu.co/portal/page/portal/Centro_Atico/presentacion1/razon_objetivo (15 de noviembre de 2012).

110 Sitio Web: http://www.webometrics.info/es (Ranking Web de Universidades Colombia, noviembre 2012).

111 Sujetos que han nacido dentro del actual entorno digital.

112 Ministerio de Tecnologías de la Información y las Comunicaciones. "Vive Digital Colombia. Versión 1.0" (2011) http://vivedigital.gov.co/files/Vivo_Vive_Digital.pdf (21 de noviembre de 2011), 11-13. 
zar hacia la convergencia digital: En el escenario 1: Se presenta la fusión de las dependencias en TIC de la universidad para producir contenidos y servicios académicos. Desde el punto de vista tecnológico, la digitalización de cualquier información (datos, sonido, imagen, vídeo) y su distribución por internet a mayores velocidades y tecnologías inalámbricas, están llevando a la tendencia de que todos los medios confluyan en un solo dispositivo. Por tanto, las universidades tenderán a integrar o fusionar sus dependencias en TIC (radio, televisión, diseño digital, educación virtual, bibliotecas virtuales, entre otras), para aunar esfuerzos tecnológicos y financieros, para maximizar sus capacidades y maneras de difundir y producir contenidos interactivos y de calidad y servicios, pasando de funciones tradicionales y aisladas a ser complementarias, para dar respuesta a las nuevas demandas de la comunidad educativa. Cabe aclarar, que algunas tenderán más hacia usos académico-administrativos, pero lo ideal sería que se centraran en usos educativos.

En el escenario 2: Se orienta a beneficiar los cambios en los hábitos de consumo de información, por parte de las comunidades académicas. A medida que la universidad amplíe su portafolio en contenidos académicos y servicios (desde hipermedios hasta alcanzar la nube computacional, en inglés Cloud Computing ${ }^{113}$, que puedan ser de acceso ubicuo desde uno o varios dispositivos (teléfonos inteligentes y/o tabletas, las cuales están bajando de precio), y si dichos recursos educativos e informativos, logran atraer a la comunidad educativa, esta aumenta la tendencia a acceder de forma habitual (apropiación), siendo los beneficiados y protagonistas en sus usos, que:

\begin{abstract}
podrán disponer de más y más variadas opciones para elegir, con el añadido de tender hacia una creciente personalización, demandando -y obteniendo- empaquetamientos y servicios a medida, tanto dependiendo de sus apetencias y necesidades personales, como en función del tiempo, el espacio y la ubicación. Al mismo tiempo, la permeabilidad antes apuntada tenderá a incrementar los niveles de competencia, con una previsible reducción en costes y precios de las prestaciones y los servicios. Y, como último atributo favorable al consumidor, hay que citar la creciente posibilidad de que sea también proveedor, aportando sus propios contenidos, ideas y soluciones a la Red ${ }^{114}$.
\end{abstract}

\footnotetext{
113 "Se utiliza para definir a un sistema informático basado en internet que permite gestionar archivos y aplicaciones sin necesidad de instarlas en la computadora" Virginia Caccuri, Computación para docentes (Buenos aires: Fox Andina, 2012), 270.

114 Enter y Centro de Análisis de la Sociedad de la Información y las Telecomunicaciones, Convergencia digital en España (Madrid: Editorial Enter, 2006), 7.
} 
Por tanto, desde el punto de vista educativo potenciará comportamientos de uso colaborativo y de interacción con otros estudiantes, docentes y culturas de forma cotidiana, participando a través de la fusión de medios digitales para construir conocimiento.

Las tecnologías digitales vienen abonando un camino de convergencia de tecnologías (microelectrónica, informática y telecomunicaciones), que ha permitido digitalizar cualquier tipo de información, prestar servicios y conectar en red, pero se encuentra en construcción un escenario más amplio, el de convergencia digital, que permite que confluyan varios medios en un único dispositivo, a lo cual se deben acoplar las universidades.

La aplicación de la tecnología en la educación y en las universidades también lleva un camino recorrido, algunas con más grado de apropiación y de escenarios de convergencia digital (televisión, radio, hipermedia, multimedia, e-learning, m-learning, web 2.0, 3.0, entre otras), que deben continuar preparándose mediante políticas, infraestructura y formación en nuevas competencias, para su comunidad académica con referencia a la fusión de medios digitales. Es de vital importancia la preparación del docente universitario ${ }^{115}$ para que, sensibilizado en la utilización de la convergencia digital, pueda desarrollar los ambientes virtuales con la calidad educativa que requiere el nivel universitario. La necesidad de estar conectado debe aprovecharse para generar cambios educativos, mediante actitudes colaborativas y de aprendizaje autónomo, que permitan el aprendizaje durante toda la vida y la construcción de conocimiento desde cualquier tiempo y lugar.

Sin embargo, no podemos pasar por alto las políticas estatales sobre la utilización de los ambientes virtuales, que se establecen en el decreto 1295, de 2010. Es más, para la obtención o renovación del registro calificado de un programa académico universitario en Colombia, se requiere que la institución garantice la disponibilidad de una plataforma tecnológica apropiada, la infraestructura de conectividad y las herramientas metodológicas necesarias para su desarrollo, así como las estrategias de seguimiento, auditoría y verificación de la operación de dicha plataforma, y está obligada a suministrar información pertinente a la comunidad sobre los requerimientos tecnológicos y de conectividad necesarios para cursar el programa.

115 Diana Soto Arango, "El profesor universitario de América Latina. Hacia una responsabilidad ética-científicosocial”, en Revista Historia de la Educación Latinoamericana, No 13, (2009), 166-188. 
En definitiva, las universidades deben centralizar su infraestructura tecnológica en una dependencia (física y administrativa), que fortalezca la convergencia digital al interior de las universidades e impacte los procesos académicos e investigativos. Por otra parte, las universidades deben ofrecer más recursos digitales e información con fines educativos. Es un hecho que el consumo digital está avanzando a una acelerada velocidad y el sistema educativo aún está discutiendo cuál debe ser el $\mathrm{ABC}$ de la alfabetización digital ${ }^{116}$. Por lo tanto, tienen la palabra los doctorados en educación ${ }^{117}$, para que desde las tesis doctorales presenten nuevas salidas curriculares, donde el sujeto social esté en primer lugar, marcando derroteros para el devenir de una sociedad más justa y equitativa en las oportunidades educativas y laborales.

\section{CONCLUSIÓN}

Partiendo de nuestras preguntas iniciales de ¿Cuáles son los nuevos retos para la calidad y la equidad en la educación superior colombiana? ¿Se están asimilando las nuevas tecnologías como la enseñanza virtual en una sociedad del conocimiento y de la información, que llevan a una individualidad y que hacen temer el diálogo personal en la universidad? Hemos establecido, en primera instancia, una reseña histórica, partiendo de la educación programada como un producto de la tecnología educativa, con el debate que se dio en los años setenta en las universidades latinoamericanas. Precisamente, desde allí nacen los imaginarios y controversias de un sistema que, para algunos, representa un nuevo método pedagógico que aísla al estudiante. Sin embargo, las mismas universidades se dieron a la tarea de realizar investigaciones sobre esta temática. Este trabajo da cuenta de nueve experiencias que avanzan, desde diferentes perspectivas, hacia la utilización de la convergencia digital, en los procesos de enseñanza y aprendizaje. Todas las investigaciones apuntan a indagar formas que conlleven a la convergencia digital, para apoyar la construcción de conocimiento, donde los sujetos sociales se adapten a estos cambios y superen las brechas digitales, generacionales y de contenidos. Se concluye como

\footnotetext{
116 Alejandro Piscitelli, "Nativos e Inmigrantes Digitales, ¿Brecha generacional, brecha cognitiva, o las dos juntas y más aún?”, en Revista Mexicana de Investigación Educativa. (2006) http://redalyc.uaemex.mx/ pdf/140/14002809.pdf. (15 de octubre de 2011).

117 Diana Soto Arango, "Los doctorados en Colombia Un camino hacia la transformación universitaria", en Revista Historia de la Educación Latinoamericana, No 12 (2009), 157-195.
} 
la convergencia digital permite la fusión de las dependencias en Tecnologías de la Información y la Comunicación (TIC) de las universidades, para producir contenidos y servicios académicos, cambios en los hábitos de consumo de información por parte de los sujetos sociales, que generarán actitudes colaborativas y de aprendizaje autónomo, que permiten aportar a los procesos de enseñanza y aprendizaje y a la construcción de conocimiento desde cualquier momento y lugar.

No es nuestro propósito exponer las bondades de un sistema que incluya la convergencia digital. Sin embargo, se puede indicar que la sociedad del conocimiento cada día cambia y que los sujetos sociales, desde los valores éticos, deben apropiarse de nuevas tecnologías en la educación, para construir una universidad que sea incluyente desde el reto de implementar la calidad en las funciones misionales, la competitividad, el reconocimiento y la cobertura estudiantil. Lo anterior, orientado hacia una sociedad más equitativa e igualitaria, incluyendo el principio de la unidad de hombres y mujeres en la diferencia y complementariedad solidarias.

Esperamos que se retomen las recomendaciones de la Misión de Sabios de 1994, de indagar en primera instancia sobre el "atraso en educación, ciencia y tecnología", desde la investigación de la función que tiene la educación y los doctorados en educación, para un cambio de valores atravesados por la solidaridad y la tolerancia en la población colombiana.

\section{FUENTES}

Congreso de la República de Colombia. Ley 1341 de 2009.

Congreso de la República de Colombia. Ley 30 de 1992.

Decreto 1295 de 2010. Colombia.

Decreto 1820 de junio 28 de 1983. Colombia.

Decreto 2277 de 1979. Colombia.

Decreto 2412 de agosto 19 de 1982. Colombia.

Documentos de política educativa del Ministerio de Educación Nacional. 2011-2012. Revisado en webs de septiembre, octubre de 2012.

Informe del Departamento Nacional de Planeación de la República de Colombia. Documento CONPES 3072 de 2000. 
SNIES, SACES, Observatorio de la Universidad. Colombia.

Tesis de Doctorado en Ciencias de la Educación. RUDECOLOMBIA.

UNESCO (2009): "La Nueva Dinámica de la Educación Superior y la búsqueda del cambio social y el Desarrollo”. CONFERENCIA MUNDIAL DE EDUCACIÓN SUPERIOR. París, Comunicado final, 05 - 08 de julio de 2009.

\section{INFOGRAFÍA}

Barreto, Anthony; Arias, Luis; Petit, Jorge. "Uso de la tecnología celular como medio de comunicación masivo”, 2008. http://www.monografias.com/trabajos62/telefonia-celular-medio-comunicacion-masivo/telefonia-celular-medio-comunicacion-masivo2.shtml.

Binde, Jerónimo. Hacia las sociedades del conocimiento. Informe mundial de la UNESCO. París: Ediciones UNESCO, 2005. www.unesco.org/publications.

Carvajal Villaplana, Álvaro. "La informática educativa: una reflexión crítica". Revista Electrónica "Actualidades Investigativas en Educación", vol. 2, No 1, (2002): http://redalyc.uaemex.mx/ pdf/447/44720102.pdf

Castillo I Merino, David. "Tecnología, economía y universidad: análisis de los efectos de las tecnologías de la información y la comunicación sobre la eficiencia económica de las universidades virtuales". Tesis Doctoral en doctorado de la Universidad Oberta de Cataluña, 2004. http://www.tdx.cat/ bitstream/handle/10803/9116/Tesi_dcastillo.pdf?sequence $=1$

Centro Ático. "Razón de ser". http://puj-portal.javeriana.edu.co/portal/page/portal/Centro_Atico/presentacion1/razon_objetivo.

Departamento Administrativo Nacional de Estadística. "Medición de las Tecnologías de la Información y las Comunicaciones. Resumen Ejecutivo". 2003. http://www.dane.gov.co/files/investigaciones/tics/tics.pdf

Finkel, Meir. "Convergencia digital". http://www.slideshare.net/meirfinkel/convergenciadigital

Finkel, Meir. “Convergencia Digital”. 2010. http://www.authorstream.com/Presentation/ meirfinkel-330259-convergencia-digital-new-tecnology-education-ppt-powerpoint/

Finquelievich, Susana y Alejandro Prince. Universidades y TICs en Argentina. Las universidades argentinas en la sociedad del conocimiento. 2005. http://www.scribd.com/doc/4940962/Finquelievich-y-PrinceLAS-UNIVERSIDADES-ARGENTINAS-EN-LA

Garavito Neira, Elkin Ramón. "Modelo de Identificación de Locutor en Entornos GMS, Aplicación". 2010. http://www.bdigital.unal.edu.co/3149/1/299634.2010.pdf

Los Hermenéuticos Cgp.Convergencia digital: una unión de conocimientos tecnológicos, http:/ / hermeneuticoscgp.blogspot.com/2011/03/convergencia-digital-una-union-de.html

Medina Alfaro, Oscar Giovanni, El estado del arte del Grid. 2011. http://www.google.com.co/ url? $\mathrm{sa}=\mathrm{t} \& \mathrm{rct}=\mathrm{j} \& \mathrm{q}=$ Investigaciones + sobre $+\mathrm{la}+$ grilla + computacional\&source $=$ web\&cd $=8$ $\& \mathrm{cad}=\mathrm{rja} \& v e d=0 \mathrm{CGIQFjAH} \& u r l=\mathrm{http} \% 3 \mathrm{~A} \% 2 \mathrm{~F} \% 2 \mathrm{Fpegasus.javeriana.edu.co} \% 2 \mathrm{~F} \sim \mathrm{CIS} 1$ 
010SD01\%2Farchivos\%2FAnexo2.docx\&ei=ydwaUbWkJYGc2QXI3YDQAw\&usg=AFQj CNHgJnJm-8nJWW8kjO7tk7RdqAN4Jw

Ministerio de Educación Nacional. "Informe de Avance Primer Semestre 2007. Programa de uso de medios y nuevas tecnologías de información y comunicaciones". (2007) http://www.colombiaaprende. edu.co/html/mediateca/1607/article-167890.html

Ministerio de Tecnologías de la Información y las Comunicaciones. "Vive Digital Colombia. Versión 1.0”. (2011). http://vivedigital.gov.co/files/Vivo_Vive_Digital.pdf.

Patiño Millán, Carlos. "Apuntes para una historia de la educación en Colombia”. http:/ /www.scribd. com/doc/35036644/APUNTES-PARA-UNA-HISTORIA-DE-LA-EDUCACION-ENCOLOMBIA

Piscitelli, Alejandro. "Nativos e inmigrantes digitales, ¿Brecha generacional, brecha cognitiva, o las dos juntas y más aún? Revista Mexicana de Investigación Educativa”. 2006. http:/ / redalyc.uaemex. $\mathrm{mx} / \mathrm{pdf} / 140 / 14002809 . \mathrm{pdf}$.

Planning de ogilvy. “¿Cómo vivimos la convergencia digital de hoy?” 2006. http:/ /www.laflecha.net/ canales/comunicacion/noticias/200607211.

Poole, Bernard. Tecnología educativa, Educar para la sociocultura de la comunicación y el conocimiento. Madrid: McGraw-Hill, 1999.

Prieto Blázquez, Josep. "Caracterización y especificación basada en ontologías de los laboratorios virtuales en las ingenierías en informática". 2006. http://openaccess.uoc.edu/webapps/o2/bitstream/10609/1474/1/tesi_jprieto.pdf.

Rivera aguilera, Alma Beatriz. "La concepción didáctica del docente y los materiales didácticos digitales: voz, texto y producción de profesores universitarios”. 1981. www.bib.uia.mx/tesis/pdf/015230/015230. pdf.

Salomon, Cindy F. What Is Digital Convergence? 2010. http://www.slideshare.net/CFSolomon/what-is-digital-convergence

Sánchez, Ana María. "Telefonía celular aplicada a educación-nuevas TIC”. 2008. http:// portal.educ. ar/debates/educacionytic/debate/post-7.php.

Strasser, Harry. Digital convergence. http:/ /www.digitalconvergence.eu/

www.rtve.es/. "UNED - Campus para la convergencia digital CONDICAMPUS". 2011. http:// www.rtve.es/alacarta/videos/uned/uned-campus-para-convergencia-digital-condicampus-04-11-11/1240657/

\section{REFERENCIAS}

Alegre Vidal, Joaquín. La gestión del conocimiento como motor de la innovación: lecciones de la industria de alta tecnología para la empresa. Castellón de la Plana: Universitat Jaume I, 2004.

Alfonso Galipienso, María Isabel. Ingeniería del software. Séptima edición. Madrid: Pearson Educación, 2005. 
Area Moreira, Manuel. Los medios y las tecnologias en la educación. Madrid: Ediciones Pirámide, 2004.

Armsey James, C.; Dahll, Norman. Tecnología de la enseñanza. México: Editorial Guadalupe, 1975.

Barbero, Jesús Martín. De los medios a las mediaciones, comunicación cultura y hegemonía. Barcelona: Anthropos, 2010.

Bates, Tony. Cómo gestionar el cambio tecnológico: estrategias para los responsables de los centros universitarios. Barcelona: Gedisa, 2001.

Bernárdez, Mariano. Diseño, producción e implementación de e-learning: Metodología, herramientas y modelos. Bloomington: AuthorHouse, 2007.

Burbano López, Galo. "La Educación Superior en la segunda mitad del siglo XX. Los alcances del cambio en América Latina y el Caribe", en Revista Iberoamericana, de Educación. Madrid: OEI, 1999.

Caccuri Virginia. Computación para docentes. Buenos aires: Fox Andina, 2012.

Castro Lechtaler, Antonio Ricardo y Fusario, Rubén Jorge. Teleinformática para ingenieros en sistemas de información. Barcelona: Editorial REVERTE, 1999.

Cavero Barca, José María; Vela Sánchez, Belén; Marcos Martínez, Esperanza. Aspectos filosóficos, psicológicos y metodológicos de la informática. Madrid: Librería-Editorial Dykinson, 2005.

Comisión de nuevos métodos de enseñanza, Enseñanza programada. México: Universidad Nacional de México, 1973.

De Pablos Heredero, Carmen; López-Hermozo, José Joaquin; Martín-Romo, Santiago; Medina, Sonia. Informática y comunicaciones en la empresa. Madrid: ESIC Editorial, 2004.

Deterline, William. Introducción a la enseñanza programada. Buenos Aires: Ediciones Troquel, 1969.

Dusenbery, Robert. Toward the 21st Century in Higher Education. Corvallis: Oregon State University Press, 1967.

Enter y centro de análisis de la sociedad de la información y las telecomunicaciones. Convergencia digital en España. Editorial Enter, 2006.

Figueiras Vidal, Aníbal Raúl. Una panorámica de las telecomunicaciones. Madrid. Pearson Educación, 2002.

Forester, Tom. Sociedad de alta tecnología: la historia de la revolución de la tecnología de la información. México: Siglo Veintiuno Editores, 1992.

García, Jacqueline. Ambiente con recursos tecnológicos escenarios para la construcción de procesos pedagógicos. San José de Costa Rica: Editorial Universidad Estatal a Distancia, 2004.

González Bernal, Edith. Formación del tutor: para la educación a distancia y los ambientes virtuales de aprendizaje en la Universidad Colombiana, 1974-2002. Colombia: Pontificia Universidad Javeriana, 2006.

Gros, Begoña, Antònia Bernat, Alejandro Catalá, Carles Feixa, Grupo F9, Javier Jaén, Pilar 
Lacasa, Rut Martínez, Laura Méndez, José Antonio Mocholí e Isidro Moreno. Videojuegos y aprendizaje. Barcelona: Grao, 2008.

Hernández González, Miguel; Prieto Pérez, José Luis. Historia de la Ciencia, vol. II. Tenerife: Fundación Canaria Orotava, 2007.

Herrera Pérez, Enrique. Introducción a las telecomunicaciones modernas. México: Editorial Limusa, 2004.

Laudon, Kenneth C.; Price Laudon, Jane. Sistemas de información gerencial: administración de la empresa. México: Pearson Educación, 2004.

Martínez Usero, José Ángel y Pablo Lara Navarra. La producción de contenidos web. Barcelona: Editorial UOC, 2007.

Ocampo López, Javier. "Darcy Riveiro: sus ideas educativas sobre la universidad y el proceso civilizatorio de América Latina”. Revista Historia de la Educación Latinoamericana No 8, 2006.

Ofiesh, Gabriel. Instrucción programada. México: Editorial Trillas, 1973.

Ortega Santamaría, Sergio. "La nueva e-universidad. Estrategias de comunicación en los portales universitarios", en Revista Académica del Foro Iberoamericano sobre Estrategias de Comunicación. No 6, Mesa III, 2007.

Osuna Acedo, Sara y Carlos Busón Buesa. Convergencias de medios: la integración tecnológica en la era digital. Barcelona: Icaria Editorial, 2008.

Otamendi Herrera, Ainhoa; Aguilar Cuenca, Diego; García Aguilera, Francisco José; Álvarez Huete, José; García Álvarez, María; Morilla Gutiérrez, Raquel; Gómez Torres, Silvia; Luque Ávila, Silvia; López Carrillo, Yolanda. Guía de innovación metodológica en e-learning. Programa EVA, 2008.

Peña Ivis, Bernardo. "Bases para un marco teórico de la tecnología educativa", en Revista Perspectivas Latinoamericanas, 1978.

Pérez, Carlos Andrés. "Herramientas computacionales para la generación de Multimedia Educativa”. Revista TEA (Tecne, Espiteme, Didaxis) (2005).

Piaget, Jean. "Science of education and the psychology of de child", en Para comprender a Piaget, editado por Mary Pulaski. Barcelona: Editorial Península, 1975.

Portman, David. The Universities and the public. A bistory of bigher adult education in the United States. Chicago: Nelson Hall, 1978.

Ríos Ariza, José Manuel; Cebrián de la Serna, Manuel. Nuevas tecnologías de la información y la comunicación aplicadas a la educación. Málaga: Ediciones Aljibe, 2000.

Rodríguez Gómez, Roberto. "Universidad y globalización. Contexto, tendencias y desafíos de la educación superior en América Latina", en Pensamiento Universitario. México: CESU, 1996.

Roldán Viloria, José. Automatismos y cuadros eléctricos. Madrid: Editorial Paraninfo, 2004.

Ruiz Velasco Sánchez, Enrique. Educatrónica: Innovación en el aprendizaje de las ciencias y la tecnología. México: Ediciones Díaz de Santos, 2007. 
Sierra, Rosaura, y Gisela Rodríguez. Feminización de la matrícula de Educación Superior en América Latina y el Caribe. México: Unión de universidades de América Latina, 2005.

Skinner, Burrhus Frederic. Walden Dos. Barcelona: Fontanella, 1973.

Skinner, Burrhus Frederic. Ciencia y conducta bumana. Barcelona: Fontanella, 1971.

Skinner, Burrhus Frederic. Tecnología de la enseñanza. Barcelona: Labor, 1970.

Soto Arango, Diana, y Olegario Negrín. "El programa de la UNED de España en Guinea Ecuatorial: una experiencia universitaria en un país del tercer mundo". Revista Vía Abierta Bogotá: (1990).

Soto Arango, Diana. "Criterios comunes para el desarrollo de una educación, universitaria global: una propuesta latinoamericana", en Politicas universitarias en América Latina, tomo II, Colección Historia y prospectiva de la universidad latinoamericana. São Paulo: Ediciones Doce Calles, 2006.

Soto Arango, Diana. "La flexibilidad curricular. Una estrategia pedagógica del siglo XXI”. Bogotá: CONACES, Ministerio de Educación Nacional, 2012.

Soto Arango, Diana. "La investigación y la innovación en los programas de Historia y Ciencias Sociales en Colombia. Una propuesta desde el Proyecto 6X4". Revista Historia de la Educación Latinoamericana. Tunja. 2007.

Soto Arango, Diana. "La investigación y la innovación en los programas de Historia y Ciencias Sociales en Colombia. Una propuesta desde el Proyecto 6X4". Revista Historia de la Educación Latinoamericana. 2007.

Soto Arango, Diana. "La Universidad Latinoamericana. Un futuro en construcción", en Independencia e Universidade Na América Latina. Tradicoes, Tempos e territórios, editado por José Rubens Lima Jardilino, Leandro de Proença Lopes, Valéria Andrade Silva. São Paulo: Paco Editorial, Sociedad de Historia de la Educación Latinoamericana, 2011.

Soto Arango, Diana. "Los doctorados en Colombia. Un camino hacia la transformación universitaria". Revista Historia de la Educación Latinoamericana. (2009).

Soto Arango, Diana. Temas de controversia en psicología del aprendizaje. Bogotá: Universidad Pedagógica Nacional, 1978. Documento inédito.

Soto Arango, Diana. "El profesor universitario de América Latina. Hacia una responsabilidad ética-científico-social”. Revista Historia de la Educación Latinoamericana, No 13, (2009): 166-188.

UNESCO, "La Nueva Dinámica de la Educación Superior y la búsqueda del cambio social y el desarrollo", en Conferencia Mundial de Educación Superior (París: Comunicado final, 2009).

Vázquez Atochero, Alfonso. Ciberantropología: cultura 2.0. Editorial UOC. 2008.

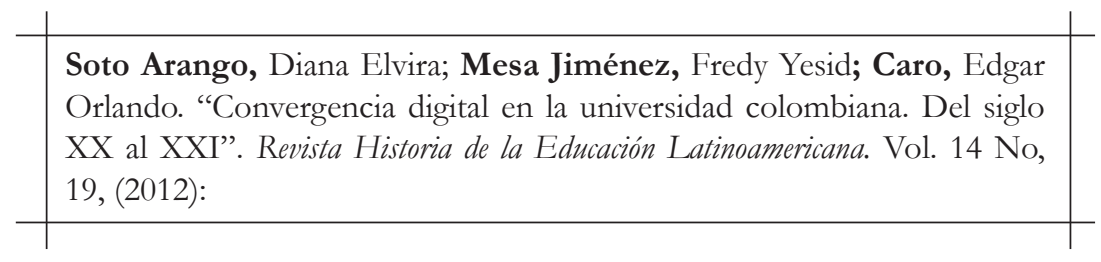

